\title{
Using lon Channel-Forming Peptides to Quantify Protein-Ligand Interactions
}

\author{
Michael Mayer $\dagger^{\star},{ }^{*}$, , Vincent Semetey $\ddagger$, Irina Gitlin $\ddagger$, Jerry Yang ${ }^{\ddagger}$, and George M. \\ Whitesides $\neq$, \\ $\dagger$ Department of Biomedical Engineering and Department of Chemical Engineering, University of Michigan, \\ Ann Arbor, MI 48109 \\ $\mp$ Department of Chemistry and Chemical Biology, Harvard University, Cambridge, MA 02138
}

\section{Abstract}

This paper proposes a method for sensing affinity interactions by triggering disruption of selfassembly of ion channel-forming peptides in planar lipid bilayers. It shows that the binding of a derivative of alamethicin carrying a covalently attached sulfonamide ligand to carbonic anhydrase II (CA II) resulted in the inhibition of ion channel conductance through the bilayer. We propose that the binding of the bulky CA II protein (MW $\sim 30 \mathrm{kD}$ ) to the ion channel-forming peptides (MW $\sim 2.5$ $\mathrm{kD}$ ) either reduced the tendency of these peptides to self-assemble into a pore, or extracted them from the bilayer altogether. In both outcomes, the interactions between the protein and the ligand lead to a disruption of self-assembled pores. Addition of a competitive inhibitor - 4carboxybenzenesulfonamide - to the solution released CA II from the alamethicin-sulfonamide conjugate and restored the current flow across the bilayer by allowing reassembly of the ion channels in the bilayer. Time-averaged recordings of the current over discrete time intervals made it possible to quantify this monovalent ligand binding interaction. This method gave a dissociation constant of $\sim 2 \mu \mathrm{M}$ for the binding of CA II to alamethicin-sulfonamide in the bilayer recording chamber: this value is consistent with a value obtained independently with CA II and a related sulfonamide derivative by isothermal titration calorimetry.

\section{Introduction}

This paper describes a method to quantify protein-ligand interactions by measuring the flux of ions through pores of a synthetically-modified, ion channel-forming peptide in planar lipid bilayers. The method is based on the reduction of ionic conductivity through self-assembled pores of a derivative of alamethicin, a naturally occurring ion channel-forming peptide, ${ }^{1-3}$ which carries a covalently attached benzenesulfonamide group on its $\mathrm{C}$-terminus (alamethicin sulfonamide, $\mathbf{8}$, see Scheme 1). In this assay, reduction of the ion current is triggered by binding of carbonic anhydrase II (CA II) to the sulfonamide moiety on the channel-forming peptide. By time-averaging the recorded current, we were able to compare the amount of transported charge before and after addition of CA II. Increasing concentrations of CA II reduced ion transport. This reduction made it possible to estimate binding constants for the interaction between CA II and the sulfonamide ligand (by plotting transported charge through the pores as a function of the concentration of CA II). Addition of a competitive inhibitor - 4carboxybenzenesulfonamide (9) - to the solution released CA II from the complex with $\mathbf{8}$ and restored the current flow through self-assembled ion channels in the bilayer.

\footnotetext{
*To whom correspondence should be addressed: E-mail: mimayer@umich.edu E-mail: gwhitesides@gmwgroup.harvard.edu.
} 
Ion channels are increasingly being investigated for sensing applications, ${ }^{4-11}$ because binding of just one ligand molecule can induce a conformational change of the ion-channel protein and result in the flux of thousands of ions. In this sense, ion channels are amplifiers, and can amplify signals by factors of $10^{3}-10^{5} .12$ This high-gain amplification makes ion channels well suited for signal transduction, which is, of course, one of their critical functions in the membranes of excitable cells. ${ }^{13}$

Based on pioneering work on protein engineering by the groups of Mutter, ${ }^{14-17}$ Montal, ${ }^{18}$, 19 DeGrado, ${ }^{20,} 21$ Vogel, ${ }^{4,} 22-25$ and Bayley, ${ }^{26-30}$ ion-channel proteins and ion-channelforming peptides have received increasing attention for sensing applications since the 1990s. 31 In 1993, Rokitskaya et al explored photodynamic inactivation of gramicidin pores in the presence of phthalocyanines. ${ }^{32}$ One year later, Bayley's group demonstrated the use of $\alpha$ hemolysin for detecting metal ions, ${ }^{26}$ and for sensing protease activity, ${ }^{33}$ while Bezrukov et al used alamethicin pores to count polymer particles. ${ }^{34}$ Woolley et al used a derivative of alamethicin to form an "ion-activated" ion channel. ${ }^{35}$ Cornell et al employed gramicidin derivatives for detection of immune reactions; ${ }^{36}$ and Vogel's group developed a synthetic ion channel $^{23}$ and detected binding of colicin $\mathrm{N}$ to the porin OmpF ${ }_{\dot{5}}^{24}$ Since these initial studies, melittin, 4, 23, 25, 37, 38 a-hemolysin, 27, 39, 40 gramicidin A, , 41-47 and alamethicin 6 , $34,48-56$ have become the most extensively studied systems for ion channel-based sensor development. The reasons for the interest in these four systems are that: i) they incorporate spontaneously into bilayers from solution (in contrast to most ion-channel proteins, which must be reconstituted into the bilayer by techniques such as proteoliposome fusion), 57 and ii) they are available commercially.

In a series of elegant studies, Bayley and coworkers showed that wild-type or geneticallymodified $\alpha$-hemolysin pores can be used to detect individual molecules, binding interactions, reversible chemical reactions, or point mutations in DNA strands. ${ }^{39,58-61}$ Despite these scientifically compelling results, the use of $\alpha$-hemolysin remains limited to specialized research laboratories. Two factors impede its widespread use: i) experiments involving planar lipid bilayers require substantial technical expertise, and the bilayers are typically only stable for hours; ii) rationally-designed modification of $\alpha$-hemolysin - using methods pioneered by Bayley - requires the tools and expertise of molecular biology. For a broader application of these systems, it would be useful if ion channel-forming peptides could be synthesized chemically at low cost, with high yield, high purity, and good stability; channel synthesis of (relatively) low molecular weight species would make it possible to produce variants at will, and to imagine certain large-volume applications that would be difficult for proteins.

Because they are commercially available, melittin, gramicidin A, and alamethicin ${ }^{62}$ might become interesting building blocks for ion-channel sensors if they could be modified synthetically. Woolley et al demonstrated, for instance, that the ion permeability through chemically-modified gramicidin pores in a lipid bilayer could be used as a pH sensor. ${ }^{42}$ In a recent proof of principle study, the groups of Mayer and Yang showed that gramicidin A can be engineered in such a fashion that makes it possible to detect specific chemically reactive agents in solution. 5,63 Futaki's group employed peptide synthesis to prepare an analogue of alamethicin with a carboxylic acid group on the C-terminal end that could be modified selectively; $6,51-53$ these authors attached a biotin group to alamethicin and demonstrated binding of streptavidin and anti-biotin antibodies. 51

Here we explored alamethicin as the platform for a sensor with three goals in mind: i) to prepare derivatives of alamethicin by chemical derivatization of commercially available alamethicin that would make this type of sensor broadly available, ii) to explore if sensors based on ion channel-forming peptides could be used to quantify protein-ligand interactions in solution, and 
iii) to investigate a "typical", biologically relevant, monovalent interaction between a protein and a small ligand. To accomplish these goals, we chose the well-characterized interaction between CA II (E.C. 4.2.1.1) ${ }^{64,65}$ and a benzenesulfonamide moiety. This interaction has a typical dissociation constant for biochemical interactions $(\sim 1 \mu \mathrm{M}) .66,67$

Alamethicin is an antimicrobial peptide composed of 19 amino acids and one amino alcohol with a molecular weight of $1.96 \mathrm{kD}$. It is secreted by the fungus Trichoderma viride. 68 Alamethicin adopts an amphipathic, $\alpha$-helical structure in biological membranes and forms ion channels by self-assembly to oligomers. The most accepted model of pore formation by alamethicin - the so-called barrel-stave model - suggests an arrangement of transmembrane helices in a circle with a central, water-filled pore. ${ }^{1,62}$ In this model the hydrophilic face on the $\alpha$-helix of alamethicin is oriented towards the lumen of the pore, whereas the hydrophobic face on the helix is in contact with the surrounding lipid molecules. 69

Alamethicin monomers in aqueous solution bind to (or dissolve in) lipid membranes with partition coefficients of $\sim 10^{-3} \mathrm{M}$. This value results in an equilibrium distribution of alamethicin in solution and alamethicin bound to the membrane (Figure 1). ${ }^{70}$ It also implies that it is relatively easy energetically to extract alamethicin from a lipid bilayer in which it is dissolved. Upon application of a transmembrane voltage, membrane-associated alamethicin molecules can adopt a transmembrane configuration in which the axis of the $\alpha$-helix is oriented perpendicular to the plain of the bilayer (alamethicin has a permanent dipole moment along this axis, which corresponds to a net $\sim+0.5$ charge at the $\mathrm{N}$-terminus of the helix and a net $\sim$ -0.5 charge at its $\mathrm{C}$-terminus ${ }^{70}$ ). The probability for alamethicin monomers to adopt this perpendicular orientation increases strongly (non-linearly) if the applied transmembrane voltage exceeds a certain threshold voltage. Once alamethicin adopts the transmembrane configuration, self-assembly of alamethicin monomers leads to pores that can comprise up to 11 monomers. ${ }^{3}$ This number of monomers in a pore fluctuates dynamically; these fluctuations lead to the characteristic stepwise changes between discrete conductance levels of single alamethicin pores. $49,50,71$ In order to perform single-channel recordings of alamethicin pores, a constant voltage above the threshold voltage has to be applied (in the work presented here, we used a transmembrane voltage of $0.14 \mathrm{~V}$ for all experiments ${ }^{49}$ ). In order to record ion flux through single alamethicin pores, the concentration of the peptide, [alamethicin], had to be low ( $\sim 5 \mathrm{nM} 8$ under the experimental conditions used in this work) to avoid the occurrence of multiple pores at the same time. ${ }^{49,72}$ Increasing the concentration of the peptide, while keeping the transmembrane potential constant above threshold, led to an increase of alamethicin monomers in the transmembrane configuration and thus to a strong increase in the probability of channel formation due to the cooperative nature of pore formation. ${ }^{62}$ The resulting "macroscopic currents" across the membrane were due to the opening of multiple (often many) pores at the same time. If we kept all other experimental parameters constant (applied voltage, ionic strength, conductance of the electrolyte, lipid composition, bilayer thickness, surface area of the planar bilayer, etc) then the "macroscopic conductance", $G$ (in $\Omega^{-1}$ or Siemens, S), through a membrane with many alamethicin pores followed the relationship:

$$
G \propto[\text { alamethicin }]^{n}
$$

where $n$, the power dependence of $G$ on the peptide concentration, has previously been used as an estimate of the average number of alamethicin monomers in the channels. This simple approach (equation 1), provides, however, at best, only a rough estimate of the average number of monomers in the channels. ${ }^{73}$ 


\section{Experimental Design}

We chose alamethicin for this study because we wanted to explore the possibility of interfering with a self-assembly process in such a way that it could be monitored in real time, and hence exploited for sensing. Six characteristics of alamethicin make this ion channel-forming peptide an interesting choice for detecting the modulation of self-assembly processes. i) Alamethicin pores are formed by the dynamic self-assembly of up to eleven monomers (in contrast to gramicidin pores that form by self-assembly of two peptides or melittin pores that form by selfassembly of four peptides); the variability of the composition of the pores results in a cooperative mechanism of pore formation and hence in a power-law of the dependence of the current through alamethicin pores on the concentration of alamethicin (equation 1). This strong (non-linear) response of the macroscopic current through alamethicin pores as a function of the alamethicin concentration is attractive for sensing, if the reaction that is used for detection can modulate this concentration and thus yield a strong response from the sensor system. ii) The self-assembly of alamethicin can be monitored with high precision and with a timeresolution below milliseconds, by using established planar bilayer recording procedures. ${ }^{49}$, 71 iii) Alamethicin is commercially available, and can be modified chemically, while preserving its ion channel-forming properties. $51,52,74$ The discrete conductance levels observed from single-channel recordings of alamethicin make it possible to examine the effect of chemical modification on the characteristics of the peptide that influence its ability to form ion channels. ${ }^{75}$ iv) Alamethicin is a relatively small molecule, and thus binding of a protein with a ten-fold larger molecular weight may be able to interfere with its self-assembly. v) Alamethicin incorporates spontaneously into bilayers; spontaneous self-assembly makes its use more practical than possible uses of most ion-channel proteins. vi) Alamethicin (or $\mathbf{8}$ in the work presented here), once it is added to the aqueous solution of a planar bilayer experiment, establishes a chain of equilibria (Figure 1) between free $\mathbf{8}$ in solution, 8 bound to the lipid bilayer, and $\mathbf{8}$ in an open, conducting pore. Assuming that molecules of $\mathbf{8}$ that are bound to CA II cannot participate in the formation of an open, conductive ion channel (either by inhibition of self-assembly of the complex of CA II-8 to a pore or by removal of CA II- $\mathbf{8}$ from the bilayer), we hypothesized that reducing any one of the concentrations of $\mathbf{8}_{\text {solution }}, \mathbf{8}_{\text {bilayer }}$, or $\mathbf{8}_{\text {pore }}$ by binding to CA II will shift these equilibria. This shift will ultimately lower the concentration of alamethicin in open pores, $\left[\mathbf{8}_{\text {pore }}\right]$. Due to the power law in equation 1 , this reduction of $\left[\mathbf{8}_{\text {pore }}\right]$ would lead to a strong reduction in the recorded transmembrane current.

For sensing applications, the stability of planar lipid bilayers is often a limiting factor. In order to generate lipid bilayers that were stable over several hours, we prepared planar membranes over micropores in Teflon films by the "folding technique" (a technique that prepares bilayers by apposition of lipid monolayers which had previously been spread at an air-water interface) for all experiments. $49,76,77$ These folded bilayers have the advantage that they form readily over small apertures (here, $<50 \mu \mathrm{m}$ ), which increases the mechanical stability and reduces the electrical noise. Moreover, folded bilayers result in so-called "solvent-free" membranes, i.e. in lipid bilayers that contain only a small amount of organic solvent. ${ }^{76} \mathrm{We}$ expected that the reduced amount of solvent would minimize fluctuations in bilayer area and thus facilitate reliable quantification of the current flux across the bilayer. ${ }^{77}$

\section{Results and Discussion}

\section{Synthesis}

In order to make sensors based on ion channel-forming peptides practical, a straightforward synthesis of the sensing element that gives the required molecule (and variants of it) in good yield and high purity is desirable. Our work constitutes a step in that direction, but is not yet a complete success. Several groups have reported methods of derivatization of alamethicin $74,78-81$ through C-terminal modification of native or synthetic alamethicin. 35 , 
82,83 The most common synthetic strategy that produces alamethicin derivatives with good to moderate ion channel activity is the formation of an ester or carbamate on the C-terminal phenylalaninol alcohol moiety of alamethicin. ${ }^{35,82-84}$ Our own attempts to make derivatives of alamethicin through esterification of the C-terminal alcohol resulted in impractically low yields, and prompted us to explore new routes to derivatization of the $\mathrm{C}$-terminus of alamethicin. Using HPLC-purified, commercially-available alamethicin (6), we demonstrated that the C-terminal alcohol of alamethicin can be oxidized under mild conditions to the corresponding aldehyde (7) in 50\% isolated yield (Scheme 1). Reaction of this aldehyde with an O-alkylated hydroxyl amine carrying a benzenesulfonamide moiety (5) afforded oxime (alamethicin sulfonamide, 8) in $48 \%$ isolated yield. Although the strategy presented in Scheme 1 is not ideal due to the requirement for HPLC purification, it is, we believe, a first step towards a practical synthesis of derivatives of alamethicin useful in the applications we envision.

\section{Ion-Channel Measurements}

In order to characterize the ion channel activity of $\mathbf{8}$, we performed single-channel recordings in a planar bilayer setup (see Experimental Section for details), ${ }^{49}$ and compared the results to native alamethicin (Scheme 1). Figure 2 shows a representative trace of current versus time for both molecules. Interestingly, $\mathbf{8}$ was capable of forming well-defined conductance states, although its single channel conductance was slightly reduced compared to native alamethicin (conductance states or conductance levels refer to assemblies of alamethicin that formed pores with discrete conductance of ions through the bilayer). This reduction was most pronounced at small conductance levels: conductance level 1 of 8 reached 52\% of conductance level 1 of native alamethicin, conductance level 2 reached $61 \%$, level 3 reached $73 \%$ and level 4 reached $78 \%$ of the conductance of the corresponding level of native alamethicin. In addition, the derivatized molecule resulted in noisier traces than native alamethicin. This additional noise may be caused by structural fluctuations of the covalently attached sulfonamide group 85 (i.e. the attached group may fold into and out of the pore) or by small-scale dynamic rearrangements of the self-assembled pore due to the presence of the sulfonamide moiety. The observation that the difference in conductance between $\mathbf{8}$ and native alamethicin was most pronounced in small pores supports the hypothesis that the sulfonamide moiety partly occluded the channel by folding towards or into it - Figure 3 illustrates schematically that such an occlusion would have a larger effect on small pores than on large pores. Figure $3 \mathrm{~B}$ and $\mathrm{C}$ show that the size of the sulfonamide group with its linker (5) relative to the size of alamethicin (6) may affect the ion channel conduction through pores of $\mathbf{8}$ if $\mathbf{5}$ were to bend towards to lumen of the pore. The energy-minimized structures in Figure $3 \mathrm{~B}$ and $\mathrm{C}$ represent only one plausible conformation of $\mathbf{8}$; the ligand $\mathbf{5}$ is expected to adopt a number of different conformations in solution.

Figure 4 illustrates the concept of an affinity sensor based on ion channel-forming peptides. The ionic conductance through a pore is modulated by specific binding of a macromolecule to the peptides that form the pore. Futaki's group proposed that in their experimental system of biotinylated alamethicin, the reduction in current was due to blocking of alamethicin pores by streptavidin or anti-biotin antibodies, which bound close to the mouth of the pore. ${ }^{51}$ Although we cannot rule out this mechanism, we believe that blocking of functional (assembled) channels would rather reduce the conductance instead of completely abolishing it as Futaki's group suggested (especially in the case of large alamethicin pores). We propose another mechanism as illustrated in Figure 4. In this mechanism binding of CA II impedes the self-assembly of alamethicin monomers due to steric hindrance of the bulky protein that is bound to the benzenesulfonamide group on this peptide (Futaki's group had mentioned this mechanism as a possibility). ${ }^{51}$ This mechanism of action, if correct, could lead to complete cessation of ion channel activity, given that the concentration of CA II is sufficiently high that the majority of $\mathbf{8}$ is bound to CA II (and that no impurities of $\mathbf{6}$ are present). Another mechanism for impeding the assembly of the pores might be extraction of monomers of $\mathbf{8}$ entirely from the bilayer by 
formation of a soluble CA II-8 complex; this complex may be less prone to membrane interactions than free $\mathbf{8}$. It is also possible that several mechanisms, including blockage of pores, 51 act in parallel or sequentially, depending on the concentration of CA II and $\mathbf{8}$.

\section{Quantitative analysis of transported charge through bilayers by time-averaging}

In the work presented here, we performed planar lipid bilayer experiments to record macroscopic currents through pores from an alamethicin derivative, $\mathbf{8}$. To determine the dependence of the recorded current, $I$, on the concentration of $\mathbf{8}$, we analyzed the ion channel current over intervals of time $t$ of five minutes. The area under the resulting current-time trace corresponded to the transported charge over the five minute interval, $Q_{5}$ :

$$
Q_{5}=\int_{t=0}^{5 \min } I(t) \cdot d t
$$

We then used this time-averaging approach to quantify the binding of CA II to 8 based on the hypothesis that the binding of the comparably bulky CA II protein (molecular weight $\sim 30 \mathrm{kD}$ ) to the comparably small peptide 8 (molecular weight $\sim 2.5 \mathrm{kD}$ ) would impede the bound molecules of $\mathbf{8}$ from participating in functional self-assembly to a conducting pore. By comparing the value of the transported charge during an interval of $5 \mathrm{~min}, Q_{5}$, before and after incubating a constant concentration of $\mathbf{8}$ with increasing concentrations of CA II, we explored the possibility of determining the binding constant between CA II and $\mathbf{8}$.

Figure $5 \mathrm{~A}$ and $5 \mathrm{~B}$ illustrate this time-averaging approach to the binding of CA II to 8 . According to equation 2, we integrated the area under the curve of current versus time (illustrated by the yellow area in Figure $5 \mathrm{~A}$ ) to obtain the total charge $Q_{5}$ (in Coulomb, C) that was transported through the bilayer over an interval of 5 minutes. Figure $5 \mathrm{~A}$ shows that a concentration of $40 \mathrm{ng} \mathrm{mL}^{-1}$ (or $16.1 \mathrm{nM}$ ) of $\mathbf{8}$ in the bilayer chamber resulted in macroscopic currents that could exceed $3 \mathrm{nA}$. Since the amplifier with the gain setting that we used cannot measure currents above $20 \mathrm{nA}$ due to current overload, we chose, somewhat arbitrarily, the concentration of $16.1 \mathrm{nM}$ of $\mathbf{8}$ as the maximum concentration that would ensure, under all conditions, that even rare current spikes with large amplitude could be recorded accurately by the amplifier. We termed the charge that was transported during 5 min through bilayers in the presence of $16.1 \mathrm{nM} \mathrm{8}$, the maximum transported charge, $Q_{5 \max }$. Since our goal was to establish a repeatable method for quantifying the binding of CA II to $\mathbf{8}$ based on the measured current through pores of $\mathbf{8}$, we had to account for variations in the surface area of the planar lipid bilayers from experiment to experiment (the solvent torus that surrounds planar bilayers can vary in thickness and area even if the same aperture is used in repeated experiments ${ }^{76,86}$ ). In order to account for these variations in bilayer area, we determined first the value of $Q_{5 \max }$ by adding $16.1 \mathrm{nM} 8$ to both bilayer chambers before starting each binding experiment. Then, after adding for instance CA II, we normalized the recorded transported charge $Q_{5}$ over the particular value of $Q_{5 \max }$ that was determined just before addition of CA II and termed the resulting normalized charge, "relative transported charge, $Q_{5 r}$ ":

Relative transported charge over 5 min: $Q_{5 r}($ in $\%)=\frac{Q_{5}}{Q_{5 \max }} \cdot 100$

Figure 6 shows that $Q_{5 r}$ depended strongly on the concentration of 8 in the recording chambers. The increase in $Q_{5 r}$ (in \%) was fitted well $\left(R^{2}=0.999, N=7\right)$ with an equation of the type: 


$$
Q_{5 r}=3.4 \cdot 10^{35} \cdot[8]^{4.3}
$$

We chose a power law based on equation 1 , since current and thus transported charge are proportional to the conductance $G$. In equation 4 , the concentration of $\mathbf{8}$ is expressed in units of $\mathrm{M}$ (i.e., $\mathrm{mol} \mathrm{L}^{-1}$ ) and the constant $3.4 \cdot 10^{35}$ is expressed in units of $\mathrm{M}^{-4.3}$.

\section{Determination of equilibrium binding constants}

Figure $6 \mathrm{~B}$ shows the effect of the addition of CA II to the compartments of the recording chamber containing $16.1 \mathrm{nM} \mathrm{8}$. The channel activity showed a strong reduction in ionic conductivity and hence in $Q_{5 r}$ upon increasing the concentration of CA II from 0 to $2 \mu \mathrm{M}$. We suggest that this reduction in trans-bilayer current was due either to disruption of the selfassembled pores, or to blocking of the pores by binding of CA II close to the mouth of the pore (Figure 4). The line in Figure $6 \mathrm{~B}$ represents a best fit to a model that is based on binding of CA II to 8. In this model, we made the following nine assumptions: i) Only "free" molecules of 8 (i.e. 8 that was not bound to CA II) could contribute to the formation of conductive alamethicin pores. This assumption does not imply that, at any given time, all free molecules of $\mathbf{8}$ actually participated in forming a pore - only the molecules of $\mathbf{8}$ that were located in the bilayer and self-assembled to pores participated in conducting channels - but it does imply that only free molecules of $\mathbf{8}$ could participate in the chain of equilibria that could lead to open pores (illustrated in Figure 1). Binding of $\mathbf{8}$ to CA II would thus effectively reduce the concentration of free $\mathbf{8}$ and consequently shift the equilibria in Figure 1 in such a way that less free $\mathbf{8}$ would be available in the bilayer to participate in the formation of conducting pores than before the addition of CA II. ii) Binding of one molecule of CA II "removed" only one molecule of $\mathbf{8}$, it did not remove aggregated clusters involving multiple molecules of $\mathbf{8}$. In contrast to this assumption, if a single molecule of CA II would block a conducting pore, then binding of each molecule of CA II would "remove" at least three molecules of $\mathbf{8}$ since the smallest conducting alamethicin pores are believed to consist of at least three (probably four) alamethicin monomers. ${ }^{87}$ The model for quantification employed here is hence different from a model that assumes blockage of alamethicin pores. iii) Non-specific binding of 8 to CA II or to the walls of the recording chambers or electrodes and stir bars could be neglected. iv) All reactions (i.e. partitioning of $\mathbf{8}$ and binding of CA II to $\mathbf{8}$ ) reached equilibrium. v) All molecules of $\mathbf{8}$ were equally accessible to CA II and vice versa. vi) Molecules of $\mathbf{8}$ were either free or bound to CA II; only one affinity state existed and no partial binding occurred. vii) Binding did not alter 8 or CA II irreversibly. viii) Binding of $\mathbf{8}$ to CA II was reversible. ix) The binding constant between $\mathbf{8}$ and CA II was the same regardless of the location where binding occurred (i.e., in solution, in the bilayer, or in a pore).

The fit to a power law in Figure 6 A yielded an empirical relationship between $Q_{5 r}$ and the total concentration of $\mathbf{8}$ in the recording chambers. Since in Figure 6 A the total concentration of $\mathbf{8}$ was equal to the free concentration of $\mathbf{8}$ (because no CA II was present and hence $\mathbf{8}$ could not be bound to CA II), we were able to use the measured values of $Q_{5 r}$ in Figure $6 \mathrm{~B}$ to calculate the concentration of free $\mathbf{8}$ at each concentration of CA II in the reaction mixture. With this information it is possible to calculate the concentration of $\mathbf{8}$ that is bound to CA II and hence to determine a binding constant by fitting the data in Figure $6 \mathrm{~B}$. In order to derive the function to fit the data in Figure $6 \mathrm{~B}$ we used the law of mass action for the binding reaction between CA II and 8:

$$
\mathrm{CA} I \mathrm{I}+\mathbf{8} \leftrightarrows \mathrm{CA} \text { II }-\mathbf{8}
$$




$$
K_{a \mathbf{8}}=\frac{[\mathrm{CA} \text { II }-\mathbf{8}]_{e q}}{[\mathbf{8}]_{e q} \cdot[\mathrm{CA} \mathrm{II}]_{e q}}
$$

where $K_{a 8}$ represents the affinity constant of the binding reaction shown in equation 5, [CA II-8 $]_{\text {eq }}$ is the molar concentration of the complex of CA II with $\mathbf{8}$ at equilibrium, $[\mathbf{8}]_{\mathrm{eq}}$ is the molar concentration of free $\mathbf{8}$ at equilibrium, and [CA II $]_{\mathrm{eq}}$ is the molar concentration of free CA II at equilibrium. Since we ultimately wanted to fit the data in Figure $6 \mathrm{~B}$, we were seeking a functional relationship between $Q_{5 r}$ and the concentration of CA II that was initially added to the recording chambers, [CA II $]_{0}$ (i.e. the concentration of CA II before binding to 8). As mentioned previously, equation 4 gave a relationship between $Q_{5 r}$ and [8]. Since we assumed that only free $\mathbf{8}$ (i.e., not $\mathbf{8}$ bound to CA II) could participate in pore formation, the concentration of $\mathbf{8}$, [8], in equation 4 referred, in this model, to the concentration of free, unbound $\mathbf{8}$ at equilibrium, $[\mathbf{8}]_{\mathrm{eq}}$. Hence, the relationship between $Q_{5 r}$ and $[\mathbf{8}]_{\mathrm{eq}}$ can be expressed as:

$$
Q_{5 r}=3.4 \cdot 10^{35} \cdot[8]_{\mathrm{eq}}{ }^{4.3} .
$$

Rearranging equation 6 yields:

$$
[\mathbf{8}]_{e q}=\frac{[\mathrm{CA} \mathrm{II}-\mathbf{8}]_{e q}}{K_{a \mathbf{8}} \cdot[\mathrm{CAII}]_{e q}} .
$$

Conservation of mass requires that equation 9 and equation 10 hold $\left([8]_{0}=16.1 \cdot 10^{-9} \mathrm{M}\right)$;

$$
\begin{gathered}
{[\mathrm{CA} \mathrm{II}-\mathbf{8}]_{\mathrm{eq}}=[\mathbf{8}]_{0}-[\mathbf{8}]_{\mathrm{eq}}} \\
{[\mathrm{CA} \mathrm{II}]_{\mathrm{eq}}=[\mathrm{CA} \mathrm{III}]_{0}-[\mathrm{CA} \mathrm{II}-\mathbf{8}]_{\mathrm{eq}} .}
\end{gathered}
$$

Since the total concentration of $\mathbf{8},[\mathbf{8}]_{0}$, in the recording chambers was low (nanomolar range) compared to the concentrations of $[\mathrm{CA} \mathrm{III}]_{0}$ that we added to the recording chambers (micromolar range), we assumed that the concentration of free CA II in equilibrium would be approximately the same as the initial concentration of CA II: ${ }^{88,} 89$

$$
[\mathrm{CA} \mathrm{III}]_{\mathrm{eq}} \approx[\mathrm{CA} \mathrm{II}]_{0} \text {. }
$$

Incorporating equation 9 and equation 11 into equation 8 yields:

$$
[\mathbf{8}]_{e q}=\frac{[8]_{0}-[8]_{e q}}{K_{a \mathbf{8}} \cdot[\mathrm{CA} \mathrm{II}]_{0}}
$$

and solving equation 12 for $[\mathbf{8}]_{\text {eq }}$ gives:

$$
[\mathbf{8}]_{e q}=\frac{[\mathbf{8}]_{0}}{K_{a \mathbf{8}} \cdot[\mathrm{CA} \mathrm{II}]_{0}+1}
$$


Finally, combining equation 13 with equation 7, gives the desired relationship between $Q_{5 r}$ and the concentration of CA II that we added to the recording chambers, $[\mathrm{CA} \mathrm{II}]_{0}$ :

$$
Q_{5 r}=3.4 \cdot 10^{35} \cdot\left(\frac{[8]_{0}}{K_{a 8} \cdot[\mathrm{CA} \mathrm{II}]_{0}+1}\right)^{4.3} .
$$

We used equation 14 to fit the data in Figure $6 \mathrm{~B}$ and obtained $K_{a 8}$ as the only fitting parameter. We performed this analysis twice; the first fit included all points in Figure $6 \mathrm{~B}$ (dotted line). This curve fit returned a value of $K_{a 8}=(3.6 \pm 1.5) \cdot 10^{5} \mathrm{M}^{-1}\left(R^{2}=0.742, N=8\right)$ corresponding to a $K_{d 8}=2.8 \mu \mathrm{M}$. Since the datum that is marked with an asterisk in Figure $6 \mathrm{~B}$ appears to be an outlier (Figure $6 \mathrm{~B}$ inset), we also performed the best fit analysis by excluding this point from the analysis (solid line). This approach returned a best fit with a value of $K_{a 8}=(6.7 \pm$ 1.5) $\cdot 10^{5} \mathrm{M}^{-1}\left(R^{2}=0.963, N=7\right)$, corresponding to a dissociation constant, $K_{d 8}=K_{a 8}{ }^{-1}=1.5$ $\mu \mathrm{M} .90$

In order to compare these values with a well established method for determining binding constants, we transformed the data in Figure $6 \mathrm{~B}$ to construct a binding isotherm (see Figure $\mathrm{S} 1$, Supporting Information). From the best curve fit analysis of this binding isotherm, we obtained a value of $K_{d \delta}=0.9 \pm 0.2 \mu \mathrm{M}$ when we excluded the outlier (marked with an asterisk in Figure $6 \mathrm{~B}$ and Figure S1) and a value of $K_{d 8}=1.3 \pm 0.3 \mu \mathrm{M}$ when we included the outlier in the best fit analysis. In summary, depending on the transformation of the original data and the corresponding best curve fit analysis, we obtained a mean value of $K_{d 8}$ ranging from 0.9 $\mu \mathrm{M}$ to $2.8 \mu \mathrm{M}$ for the interaction between $\mathbf{8}$ and CA II in the recording chambers.

For comparison with an independent method, we measured the affinity constant of CA II with benzenesulfonamide (5) by isothermal titration calorimetry (ITC). ${ }^{91}$ We used precursor (5) for the ITC measurement because it was more soluble in aqueous solutions than $\mathbf{8}$; this increased solubility was required to achieve detectable reagent concentrations for ITC measurements. The resulting dissociation constant $K_{d 5}$ by ITC was $2.6 \pm 0.6 \mu \mathrm{M}$, which compares well with the range of $0.9-2.8 \mu \mathrm{M}$ obtained with the ion channel system presented here.

\section{Competitive binding assay; displacement of 8 from CA II}

To test if it was possible to displace the bound molecules of $\mathbf{8}$ from CA II by competitive binding, we added increasing concentrations of a competitive inhibitor, 9 (Scheme 1), to both compartments of a recording chamber which contained a total concentration of $16.1 \mathrm{nM}$ of 8 and $9.3 \mu \mathrm{M}$ of CA II (i.e., $[8]_{0}=16.1 \mathrm{nM}$; [CA II $]_{0}=9.3 \mu \mathrm{M}$ ). We expected 9 to be able to displace 8 from Ca II because the dissociation constant for binding of 9 to CA II, $K_{d \boldsymbol{g}}$, is 0.73 $\pm 0.02 \mu \mathrm{M} .{ }^{67}$ Figure 7 (data shown as squares) shows that increasing concentrations of 9 resulted in an increase in the relative transported charge $Q_{5 r}$ through the bilayer. This increase corresponded to an increased concentration of free $\mathbf{8}$ in solution as expected if $\mathbf{9}$ displaced $\mathbf{8}$ from the CA II-8 complex. The square-shaped points in Figure 7 could be fitted well $\left(R^{2}=\right.$ $0.999, N=4$ ) with a dose-response curve (solid curve) of the following form: ${ }^{93}$

$$
y=y_{\min }+\frac{y_{\max }-y_{\min }}{1+10^{\left(\log E C_{50}-x\right) \cdot \text { HillSlope }}},
$$

where $y$ corresponds to $Q_{5}, y_{\min }$ represents the lower asymptotic value of the sigmoidal function, $y_{\max }$ represents the upper asymptotic value, $\log E C_{50}$ represents the logarithm of the concentration that generates $50 \%$ response $\left(E C_{50}\right), x$ corresponds to $\log [9]_{0}$, and HillSlope ${ }^{94}$ determines the steepness of the curve. 
Before fitting the data (squares) in Figure 7 to equation 15, we set $y_{\min }$ to $0.1 \%$ since we measured this value of $Q_{5 r}$ experimentally before adding 9 (i.e. [9] $]_{0}=0$ ) and we set $y_{\max }$ to $100 \%$ since we assumed that at high concentrations of competitive ligand (here $[9]_{0}>1 \mathrm{mM}$ ), virtually all $\mathbf{8}$ would be released from the CA II-8 complex (i.e., $[\mathbf{8}]_{\mathrm{eq}} \approx[\mathbf{8}]_{0}=16.1 \mathrm{nM}$ ) and that consequently the relative transported charge $Q_{5 r}$ would reach $100 \% .{ }^{95}$ The best fit analysis of the square points returned a value for $\log E C_{50}$ of $-4.62 \pm 0.01$, corresponding to $E C_{50}=24.2 \mu \mathrm{M}$ and a value for the HillSlope of $4.51 \pm 0.04 .96$

In order to determine the dissociation constant $K_{d 9}$ for the interaction between CA II and 9 based on the competitive binding data in Figure 7, we used an approach developed by Linden in $1982 .{ }^{97}$ This approach makes it possible to calculate the dissociation constant from competitive binding curves without the requirement that the concentration of any of the involved species has to remain constant (i.e., it allows for depletion of all species). We used this approach for accurate determination of $K_{d \boldsymbol{g}}$ because we expected that the addition of micromolar concentrations of $\mathbf{9}$ to the recording chambers which contained nanomolar concentrations of $\mathbf{8}$ and micromolar concentrations of CA II would lead to significant changes in the equilibrium concentrations of free molecules of $\mathbf{8 , 9}$, and CA II. Simplifications such as the one made in equation 11 would not be appropriate for determining $K_{d \varphi}$ in this case.

Application of Linden's approach proceeded in three steps. First we used the competitive binding data in Figure 7 to determine the "inhibitory" concentration of 9 that displaced 50\% of 8 from CA II, i.e. the $I C_{50}$ concentration for competitive binding of 9 to CA II in the presence of 8 (Figure 7) We determined the $I C_{50}$ value by plotting $\Theta_{8 \text {, bound, which is defined as }}$

$$
\Theta_{\mathbf{8}, \text { bound }}=\frac{[\text { CA II }-\mathbf{8}]_{e q}}{[\mathbf{8}]_{0}}=\frac{[\mathbf{8}]_{0}-[\mathbf{8}]_{e q}}{[\mathbf{8}]_{0}},
$$

as a function of [9] (round symbols in Figure 7) and followed by fitting the data with an equation for competitive binding: 92

$$
y=y_{\min }+\frac{y_{\max }-y_{\min }}{1+10^{\left(x-\log I C_{50}\right) \cdot \text { HillSlope }}}
$$

where $y$ corresponds to $\Theta_{8 \text {, bound }}, y_{\min }$ and $y_{\max }$ represent the lower and the upper asymptotic value of the sigmoidal function, $x$ corresponds to $\log [9]_{0}, \log I C_{50}$ represents the logarithm of the $I C_{50}$ concentration, and HillSlope determines the steepness of the curve. We set $y_{\min }$ to 0 , since we assumed that at large concentrations of $\mathbf{9}$, all CA II molecules would be bound to 9 and hence $\Theta_{8 \text {, bound }}$ would be 0 . In order to obtain the value of $y_{\max }$, we calculated $\Theta_{8 \text {, bound }}$ before addition of 9 (i.e. [9] $]_{0}=0$ ) in two steps. We first used equation 13 to calculate $[\mathbf{8}]_{\mathrm{eq}}$ by employing the previously determined value of $K_{a 8}=6.7 \cdot 10^{5} \mathrm{M}^{-1}$ and a value of [CA II $]_{0}=$ $9.3 \cdot 10^{-9}$ as well as a value of $[8]_{0}=16.1 \mathrm{nM}$; with these values we obtained $[8]_{\mathrm{eq}}=2.2 \cdot 10^{-9}$ M. Second, by using this value for $[8]_{\mathrm{eq}}$ and equation 16 , we obtained a value of $\Theta_{8}$, bound $=$ 0.86 . Consequently, we used this value of 0.86 for $y_{\max }$ to perform the best curve fit of the blue points in Figure 7 with equation 17. This analysis generated the following two values: $\log I C_{50}=-4.89 \pm 0.04$, and HillSlope $=2.22 \pm 0.44\left(R^{2}=0.981, N=4\right) .{ }^{96}$ Hence the mean value for the $I C_{50}$ concentration for displacement of $\mathbf{8}$ from CA II by adding 9 was $12.9 \mu \mathrm{M}$.

Second, from this value of $I C_{50}$ we calculated the concentration of 9 that was free in the equilibrium mixture $[\mathbf{9}]_{\mathrm{eq}}$ when the total concentration of $\mathbf{9},[\mathbf{9}]_{0}$, was equal to the $I C_{50}$ (i.e., $\left.[\mathbf{9}]_{0}=12.9 \mu \mathrm{M}\right)$ with the following equation: ${ }^{97}$ 
For this calculation, we first computed the value of $[8]_{\text {eq }}$ when $[9]_{0}=12.9 \mu \mathrm{M}$ in two steps: i) equation 14 yielded a value of $Q_{5 r}=5.7 \%$ when $[9]_{0}=12.9 \mu \mathrm{M}$ and ii) from this value of $Q_{5}$, equation 7 yielded the value of $[8]_{\mathrm{eq}}=8.2 \mathrm{nM}$. The remaining two values that we used to calculate [9] $]_{\mathrm{eq}}$ with equation 18 were $K_{d 8}=1.5 \mu \mathrm{M}$ and [CA II $]_{0}=9.3 \mu \mathrm{M}$. With these parameters, equation 18 returned a value of $[9]_{\mathrm{eq}}=4.8 \mu \mathrm{M}$.

And in the third and final step, we used the value of $[9]_{\mathrm{eg}}=4.8 \mu \mathrm{M}$ and the following formula derived by Linden to calculate the desired value of $K_{d} 9.97$

$$
K_{d \mathbf{9}}=\frac{[\mathbf{9}]_{e q}}{1+\frac{[8]_{e q}}{K_{d 8}}+\frac{[\mathrm{CA} \mathrm{III}]_{0}}{K_{d 8}}\left(\frac{K_{d 8}+\frac{[8]_{e q}}{2}}{K_{d 8}+[8]_{e q}}\right)},
$$

with $[8]_{\mathrm{eq}}=8.2 \mathrm{nM}, K_{d 8}=1.5 \mu \mathrm{M}$, and [CA II $]_{0}=9.3 \mu \mathrm{M}$, we obtained a value for $K_{d \boldsymbol{g}}=0.7$ $\mu \mathrm{M}$. If we repeated this analysis by employing the range of values for $K_{d 8}$ that we determined previously $\left(K_{d 8}=0.9-2.8 \mu \mathrm{M}\right)$, we obtained a range from $0.4 \mu \mathrm{M}$ to $1.2 \mu \mathrm{M}$ for the dissociation constant $K_{d}$. The value of $0.7 \mu \mathrm{M}$ for $K_{d g}$ is in excellent agreement with the dissociation constant of $0.73 \pm 0.02 \mu \mathrm{M}$ determined for the same interaction (i.e. for binding of 4carboxybenzenesulfonamide (9) to CA II) by isothermal titration calorimetry. 67

\section{Practicability of quantifying protein-ligand interactions with ion channel-forming peptides}

In asking if the approach described here offers a broadly applicable assay platform, we see three major challenges. First, the preparation of planar bilayers of high quality requires expertise, experimental skill, and appropriate equipment, which includes a low noise current amplifier, a data acquisition board with adequate software, a Faraday cage, and typically a vibration-damping platform. Second, planar lipid bilayers are inherently metastable systems; their lifetime typically ranges from a few minutes to a few hours. When membranes broke, it was often necessary to wash the entire setup and start a new experiment. Since the analysis presented here was based on equilibrium conditions of binding, it took several hours to record entire dose-response curves. Hence in some cases only a part of the dose-response curves could be completed with a given bilayer. Third, it can be difficult to keep the bilayer area of a planar lipid membrane constant over minutes to hours. Fluctuations in bilayer area (due to fluctuations of the area and thickness of the torus) could cause fluctuations in transported charge, and these fluctuations could occur within one dose-response curve, potentially leading to inaccuracies of $Q_{5 r}$. For each new bilayer, we measured the capacitance of the membrane - a quantity that is proportional to the bilayer area - and waited until the capacitance appeared to reach a nearly constant value. For some membranes this waiting period could take tens of minutes. Then we measured $Q_{5 \max }$ for this particular membrane before adding CA II or $\mathbf{9}$. In some cases we measured only a limited number of concentrations of a dose-response curve and then purposely prepared a new membrane in order to minimize possible fluctuations of the membrane area over long periods of time.

The assays presented here, although promising and remarkably accurate with respect to the determined dissociation constants, are thus, in their current configuration, not practical for realworld sensor applications; they are best performed under well-defined conditions in research laboratories relatively proficient in ion-channel biochemistry. One potential strategy to reduce 
problems with changing bilayer areas might be to perform the assays on apertures with large diameters (e.g. $500 \mu \mathrm{m})$ rather than the small diameters that we chose $(<50 \mu \mathrm{m})$. If these large apertures would be prepared in very thin polymer films, then the surface area of the membrane that would be occupied by the torus would be relatively small compared to the bilayer area over these large pores. Fluctuations in the area of the torus may thus have a relatively small effect. Planar lipid bilayers over large diameter pores are, however, less stable than bilayers over small pores (which is the reason why we chose small pores in this work) and the large capacitance of these membranes generates large current noise in the recordings. ${ }^{49}$ Recent developments of hydrogel-embedded planar lipid bilayers may, however, make it possible to extend the lifetime of these bilayers. 98

\section{Conclusion}

Using a system of CA II and alamethicin covalently attached to a sulfonamide ligand, we demonstrated that binding of a protein to an ion channel-forming peptide that carries a ligand can be used to quantify protein-ligand interactions by measuring the inhibition of ion channel activity upon binding. Time-averaging of the current transported through the bilayer made it possible to determine the dissociation constant for this monovalent protein-ligand interaction. The resulting assay could be carried out in small volumes of solution (here $3 \mathrm{~mL}$ but volumes smaller than $50 \mu \mathrm{L}$ have been used for planar lipid bilayer recordings of alamethicin activity ${ }^{50}$ ) and required nanomolar concentrations of the ion channel-forming peptide (here alamethicin sulfonamide) as well as low micromolar concentrations of the protein (here CA II).

In order to make this type of ion channel-based affinity sensors practical, the synthetic route for attaching ligands to alamethicin will have to be simplified, ideally to a degree that it could be carried out by non-chemists. The work presented here is only a first step in this direction since it starts from commercially available building blocks. The overall yield was only moderate, and the purification required expertise in preparative HPLC techniques. Further requirements are that the ligands should have low molecular weight and must be chemically amenable for covalent coupling to the pore-forming peptide; they also must be sufficiently stable to withstand the coupling reaction without changing their physico-chemical properties. As with most applied experiments on planar lipid bilayers, the mechanical ${ }^{49}$ and thermodynamic stability 99 of the bilayers would have to be improved before such sensors will yield widely-used, robust, and user-friendly assays. Quantitative analyses of changes in the transported charge through pores of ion channel-forming peptides as a function of the addition of an analyte pose an additional challenge: the area of the lipid bilayer has to be kept as constant as possible or correction strategies have to be developed that take into account possible fluctuations in bilayer area over time. One possible strategy may be frequent measurements of the electrical capacitance of the bilayer and normalizing the relative transported charge over the membrane capacitance (or the bilayer area, which is proportional to the membrane capacitance). Another strategy may be to embed the bilayer into a hydrogel polymerized in $s i t u$. The hydrogel can stabilize the torus of the membrane and thus minimize fluctuations in area of the bilayer. 98

We believe that the active research efforts in the area of microfabricated planar lipid bilayer setups, $4,25,49,50,71,98,100-110$ as well as in the area of synthesizing functional derivatives of ion channel-forming peptides, $5,7,28,29,35,42,43,63,82,104,111,112$ will help to overcome - at least to some extent - these challenges of affinity sensors based on ion channels. If so, these sensors might make it possible to perform quantitative affinity assays in volumes below $50 \mu \mathrm{L}$ and at concentrations of ligand and receptor below $10 \mu \mathrm{M}$. Their advantage might thus be to require only sub-nanomole amounts of receptor and ligand. 
In comparison to existing methods such as isothermal titration calorimetry, the method presented here has the advantage that it is a single molecule method in the sense that the flux of ions through a single assembled pore can be monitored readily and with a time resolution below milliseconds. Another advantage compared to isothermal titration calorimetry is that sensing with ion channels requires significantly lower concentrations of ligand (here $\mathbf{8}$ ) and the detection mechanism is, in principle, strikingly simple (i.e. applying a small constant voltage and measuring a small current over time). In addition, the footprint of the entire experimental setup can be small making this method attractive for potential applications as portable sensors. ${ }^{113-115}$

Moreover, sensing with ion channels is an amplifying method, and has some analogy to standard affinity assays such as enzyme-linked immunosorbent assays (ELISAs), which utilize the amplification provided by enzymatic turnover. This method takes advantage of the inherent amplification of ion channels in the sense that one channel can conduct thousands of ions per millisecond. Another advantage of channel-based sensing is that it is not sensitive to colored samples or samples that might contain quenchers of fluorescence or inhibitors of the enzymes that are used for amplification. ${ }^{63}$ In addition, ion channel-based sensing can, presumably, proceed in solution as long as the affinity interaction reduces the concentration of free channelforming peptide and thus shifts the equilibria in Figure 1 in the direction of reduced concentrations of peptide in a functional pore. ELISA assays, in contrast, are inherently surfacebased assays.

Nonetheless, at this stage, ELISA assays provide superior robustness and ease of use compared to the channel-based affinity assay demonstrated in this report. Compared to isothermal titration calorimetry, sensing with ion channels has the disadvantage that it requires derivatization of the ion channel-forming peptide to attach each ligand of interest. Moreover, as opposed to isothermal titration calorimetry, sensing based on ion channels does not provide thermodynamic quantities such as changes in enthalpy. Compared to both methods, ELISA and isothermal titration calorimetry, sensing with ion channels, at this stage of development, is hampered by the stability of the bilayers, which is limited to periods of minutes to hours.

In order to carry out the analysis presented here, we proposed that the disruption and restoration of self-assembly of a derivative of alamethicin can be used for quantifying receptor ligand interactions. Although we did not provide definite proof for this mechanism of detection, we think that the excellent agreement of the determined dissociation constants with literature values support this mechanism. Based on these results, we suggest that utilizing the disruption or restoration of self-assembly for sensing applications is a fundamentally interesting and promising avenue since self-assembly is often a cooperative process and may thus respond strongly to specifically engineered disturbances.

\section{Experimental Section}

\section{Materials}

All chemicals, including bovine CA II (CA II, pI 5.9, E.C. 4.2.1.1), were purchased from Sigma-Aldrich (St. Louis, MO) unless stated otherwise. Mass spectra were performed by matrix-assisted laser desorption/ionization mass spectrometry (MALDI-TOF) using $\alpha$ cyano-4-hydroxycinnamic acid as matrix. All analytical HPLC separations were run with a Microsorb C18 column $5 \mu \mathrm{m}(4.6 \times 250 \mathrm{~mm})$ using a linear gradient from $A(100 \%$ water containing $0.1 \%$ TFA) to $B(100 \%$ acetonitrile containing $0.08 \%$ TFA), at a flow rate of 1.2 $\mathrm{mL} \min ^{-1}$ (UV dectection at 214 and $254 \mathrm{~nm}$ ). Alamethicin with a purity >90\% (HPLC) was purchased from Sigma (St. Louis, MO). We started with commercial alamethicin (6) (isolated from Trichoderma viride) and separated the two alamethicin variants (F30 and F50), by HPLC on $\mathrm{C} 18$ column $5 \mu \mathrm{m}(10 \times 250 \mathrm{~mm})$ using a linear gradient of $70 \% \mathrm{~A}$ with $30 \% \mathrm{~B}$ to $100 \%$ 
$B$ over $40 \mathrm{~min}$ at a flow rate of $5 \mathrm{~mL} \mathrm{~min}-1$. We used the $\mathrm{F} 30$ fraction for all experiments; fractions containing alamethicin $\mathrm{F} 30$ were combined and evaporated to dryness (purity $>99 \%$ ). MS (MALDI-TOF) $m / z: 1965.77[\mathrm{M}+\mathrm{H}]^{+}$, calculated for $\mathrm{C}_{92} \mathrm{H}_{151} \mathrm{~N}_{22} \mathrm{O}_{25}{ }^{+}[\mathrm{M}+\mathrm{H}]^{+} 1965.32$.

F30 : Ac-Aib-Pro-Aib-Ala-Aib-Ala-Gln-Aib-Val-Aib-Gly-Leu-Aib-Pro-Val-Aib-Aib-GluGln-Phenylalaninol

F50 : Ac-Aib-Pro-Aib-Ala-Aib-Ala-Gln-Aib-Val-Aib-Gly-Leu-Aib-Pro-Val-Aib-Aib-GlnGln-Phenylalaninol

\section{Compound 1}

Acid 1 was prepared as described by Avila et al. ${ }^{116}$ The yield $89 \%$ and the product was pure. ${ }^{1} \mathrm{H}$ NMR $\left(400 \mathrm{MHz}\right.$, DMSO- $\left.d_{6}\right)=\delta 1.53(\mathrm{~m}, 4 \mathrm{H}), 2.17(\mathrm{t}, 2 \mathrm{H}), 2.32(\mathrm{t}, 2 \mathrm{H}), 3.58(\mathrm{~s}, 3 \mathrm{H})$, $4.32(\mathrm{~d}, 2 \mathrm{H}), 7.33(\mathrm{~s}, 2 \mathrm{H}), 7.41(\mathrm{~d}, 2 \mathrm{H}), 7.77(\mathrm{~d}, 2 \mathrm{H}), 8.43(\mathrm{t}, 1 \mathrm{H})$. HRMS (FAB) $\mathrm{m} / z: 329.1181$ $[\mathrm{M}+\mathrm{H}]^{+}$, calculated for $\mathrm{C}_{14} \mathrm{H}_{21} \mathrm{~N}_{2} \mathrm{O}_{5} \mathrm{~S}^{+}[\mathrm{M}+\mathrm{H}]^{+} 329.1171$.

\section{Compound 2}

Compound 2 was synthesized according to Roy and Mallik. $117{ }^{1} \mathrm{H}$ NMR $(400 \mathrm{MHz}, \mathrm{MeOH} /$ $\left.\mathrm{CDCl}_{3}\right)=\delta 2.82(\mathrm{t}, 2 \mathrm{H}), 3.35-3.39(\mathrm{~m}, 2 \mathrm{H}), 3.53-3.66(\mathrm{~m}, 6 \mathrm{H}), 5.07(\mathrm{~s}, 2 \mathrm{H}), 7.31-7.34(\mathrm{~m}$, $5 \mathrm{H})$.

\section{Compound 3}

To a solution of (Boc-aminooxy)acetic acid $(0.437 \mathrm{~g}, 2.29 \mathrm{mmol}), N$-ethyl- $N$ 'dimethylaminopropylcarbodiimide. $\mathrm{HCl}(0.438 \mathrm{~g}, 2.29 \mathrm{mmol})$ and $\mathrm{N}, \mathrm{N}$-diisopropylethylamine $(1.09 \mathrm{~mL}, 6.24 \mathrm{mmol})$ in dimethylformamide $(5 \mathrm{~mL})$ was added $2(0.587 \mathrm{~g}, 2.08 \mathrm{mmol})$, and the solution was stirred at room temperature for $5 \mathrm{~h}$. The solution was evaporated, and the product partitioned between ethyl acetate and water. The organic layer was washed with water $(2 \times 50 \mathrm{~mL})$, dried over sodium sulfate, and evaporated to dryness. The crude compound was chromatographed $\left(\mathrm{SiO}_{2}\right.$, using $100 \%$ ethyl acetate as eluent) to yield $\mathbf{3}(530 \mathrm{mg}, 1.16 \mathrm{mmol}$, $56 \%$ yield $)$ as a clear oil. ${ }^{1} \mathrm{H}$ NMR $\left(500 \mathrm{MHz}, \mathrm{CD}_{3} \mathrm{OD}\right)=\delta 1.46(\mathrm{~s}, 9 \mathrm{H}), 1.57-1.69(\mathrm{~m}, 4 \mathrm{H})$, $3.29(\mathrm{t}, 2 \mathrm{H}), 3.43(\mathrm{t}, 2 \mathrm{H}), 3.54(\mathrm{t}, 2 \mathrm{H}), 3.57(\mathrm{t}, 2 \mathrm{H}), 3.61(\mathrm{~s}, 4 \mathrm{H}), 4.25(\mathrm{~s}, 2 \mathrm{H}), 5.07(\mathrm{~s}, 2 \mathrm{H})$, 7.25-7.38 (m, 5H); MS (MALDI-TOF) $\mathrm{m} / z$ 478.74 [M + Na] $]^{+}$, calculated for $\mathrm{C}_{21} \mathrm{H}_{33} \mathrm{~N}_{3} \mathrm{NaO}_{8}+[\mathrm{M}+\mathrm{Na}]^{+} 478.51$.

\section{Coumpound 4}

Compound 3 (157 mg, $0.34 \mathrm{mmol})$ and $10 \% \mathrm{Pd} / \mathrm{C}(20 \mathrm{mg})$ were combined in ethanol $(20 \mathrm{~mL})$. This mixture was hydrogenated at atmospheric pressure and room temp for two hours. The mixture was then filtered through Celite, the filter cake washed with $2 \times 10 \mathrm{~mL}$ of ethanol, and the resulting solution was concentrated by evaporation. The acid $\mathbf{1}(119 \mathrm{mg}, 0.38 \mathrm{mmol}), \mathrm{N}-$ ethyl-N'-dimethylaminopropylcarbodiimide. $\mathrm{HCl}(73 \mathrm{mg}, 0.38 \mathrm{mmol})$ and N,Ndiisopropylethylamine $(180 \mu \mathrm{L}, 1.03 \mathrm{mmol})$ were combined in $5 \mathrm{~mL}$ of DMF at room temperature with stirring, and the reaction was allowed to proceed at room temperature overnight. The crude product was purified by HPLC (linear gradient, $100 \% A$ to $80 \% \mathrm{~B}$, over $40 \mathrm{~min}$ ) and lyophilized to afford 4 (111 mg, $0.18 \mathrm{mmol}, 52 \%$ yield) as a clear oil. ${ }^{1} \mathrm{H}$ NMR $\left(500 \mathrm{MHz}, \mathrm{CD}_{3} \mathrm{OD}\right) \delta 1.47(\mathrm{~s}, 9 \mathrm{H}), 1.57-1.69(\mathrm{~m}, 4 \mathrm{H}), 2.22(\mathrm{t}, 2 \mathrm{H}) 2.28(\mathrm{t}, 2 \mathrm{H}), 3.35(\mathrm{t}, 2 \mathrm{H})$, $3.44(\mathrm{t}, 2 \mathrm{H}), 3.54(\mathrm{t}, 2 \mathrm{H}), 3.58(\mathrm{t}, 2 \mathrm{H}), 3.62(\mathrm{~s}, 4 \mathrm{H}), 4.25(\mathrm{~s}, 2 \mathrm{H}), 4.43(\mathrm{~s}, 2 \mathrm{H}), 7.44(\mathrm{~d}, 2 \mathrm{H})$, $7.85(\mathrm{~d}, 2 \mathrm{H})$; analytical HPLC $t_{\mathrm{R}} 12.77 \mathrm{~min}$ (linear gradient, $100 \% A$ to $100 \% \mathrm{~B}$, over $20 \mathrm{~min}$ ); MS (MALDI-TOF) $m / z 618.27[\mathrm{M}+\mathrm{H}]^{+}$, calculated for $\mathrm{C}_{26} \mathrm{H}_{44} \mathrm{~N}_{5} \mathrm{O}_{10} \mathrm{~S}^{+}[\mathrm{M}+\mathrm{H}]^{+} 618.72$. 


\section{Alamethicin-Sulfonamide, 8}

To a solution of alamethicin F30 ( $8 \mathrm{mg}, 4.08 \mu \mathrm{mol})$ in dichloromethane, Dess-Martin periodinane $(17.3 \mathrm{mg}, 40.82 \mu \mathrm{mol})$ was added. ${ }^{118}$ The mixture was filtered and concentrated to a solid by evaporation. The crude peptide derivative was purified by preparative HPLC (linear gradient, $70 \% A$ with $30 \% B$ to $100 \% B$, over $40 \mathrm{~min}$ ), and the solution evaporated to afford alamethicin aldehyde 7 (4 mg, $2.04 \mu \mathrm{mol})$ as a white solid. No impurities were detected by analytical HPLC (linear gradient, $100 \% A$ to $100 \%$ B over 20 minutes). The Boc-protected compound $4(6.3 \mathrm{mg}, 10.21 \mu \mathrm{mol})$ was dissolved in $10 \mathrm{~mL}$ of trifluoroacetic acid and stirred for $30 \mathrm{~min}$ at room temperature. The solution was evaporated to dryness. The residue was dissolved in methanol $(1 \mathrm{~mL})$ and $7(4 \mathrm{mg}, 2.04 \mu \mathrm{mol})$ was added. The reaction was allowed to proceed for $2 \mathrm{~h}$, and then evaporated. The crude peptide derivative was purified by HPLC (linear gradient, $70 \% A$ with $30 \% B$ to $100 \% B$, over $40 \mathrm{~min}$ ) and evaporated to afford 8 (2.4 $\mathrm{mg}, 0.97 \mu \mathrm{mol}, 24 \%$ yield) as white solid. HPLC $t_{R} 14.20$ and $14.42 \mathrm{~min}$ (linear gradient, $70 \%$ $A$ with $30 \% B$ to $100 \% B, 20 \mathrm{~min}$ ); MS (MALDI-TOF) $\mathrm{m} / z 2484.38[\mathrm{M}+\mathrm{Na}]^{+}$, calculated for $\mathrm{C}_{113} \mathrm{H}_{181} \mathrm{~N}_{27} \mathrm{NaO}_{32} \mathrm{~S}^{+}[\mathrm{M}+\mathrm{Na}]^{+} 2484.86$.

\section{Molecular Modeling}

We generated the energy minimized structure shown in Figure 3 B, C using molecular mechanics calculations employing AMBER force field parameters in water (MacroModel software, version 7.5, Schroedinger Inc.). We constructed $\mathbf{8}$ in silico by modification of the Cterminus of the crystal structure of 6 (1AMT from the Protein Data Bank) in MacroModel. For this calculation, the residues of the alamethicin peptide (6) were fixed during the conformational analysis. We allowed the ligand (5) to rotate freely during these calculations. After performing 5000 iterations of conformational analysis of $\mathbf{8}$, we selected the lowest energy conformation.

\section{Planar lipid bilayer experiments}

We used the same experimental setup and procedure as described in detail by Mayer et al. ${ }^{49}$ Briefly, we prepared Teflon AF films by molding a solution of $6 \%$ Teflon AF in Fluorinert FC-75 solvent (DuPont Fluoroproducts, Wilmington, DE) around a sharp tip (gold-plated tungsten probe tips with a nominal tip diameter of $10 \mu \mathrm{m}$ from Lucas Signatone, Gliroy, CA) that was oriented perpendicular to, and placed in contact with, a silicon wafer such that the tip rested on the wafer by gravity. Before casting the Teflon AF solution, the wafer was treated with an air plasma followed by silanization with tridecafluoro-1,1,2,2-tetrahydrooctyl)-1trichlorosilane (United Chemical Technologies, Bristol, PA) under vacuum $(60 \mathrm{~mm} \mathrm{Hg}$ ) to facilitate the removal of the film of Teflon AF from the wafer after evaporation of the solvent).

Before using these Teflon AF sheets for planar lipid bilayer experiments, we treated ${ }^{119}$ the area close to the pores with a solution of 5\% squalene (Sigma, St. Louis, MO) in pentane (Sigma-Aldrich, St. Louis, MO) by dipping the tip of a tissue paper first into the squalene solution and then moving it over the area close to the pore in the Teflon film. ${ }^{120}$ We formed all bilayers by the "folding technique" 49,121 in which two monolayers of lipids at an airelectrolyte interface are raised such that their acyl chains face each other and span over the aperture in the Teflon AF support. The result of this procedure is a lipid bilayer that spans the aperture in the Teflon AF film and separates the two compartments of the lipid bilayer chamber (each compartment was filled with $3.5 \mathrm{~mL}$ of aqueous electrolyte containing $1.0 \mathrm{M} \mathrm{KCl}$ ). 122 To prepare the lipid monolayers, we spread a volume of $2-10 \mu \mathrm{L}$ of a lipid solution in pentane containing a 1:1 mixture of L-a-phosphatidylserine from brain and 1-palmitoyl-2oleoyl-sn-glycero-3-phosphoethanolamine, both from Avanti Polar Lipids, Alabaster, AL with a concentration of $\sim 12 \mathrm{mg} \mathrm{mL}^{-1}$ of each lipid on the electrolyte solution in each chamber. We raised and lowered the liquid level of one compartment with a $3 \mathrm{~mL}$ syringe until we measured an electrical resistance of $\geq 10 \mathrm{G} \Omega$ between both compartments to verify that a bilayer without 
leak currents was obtained. We recorded the current (and hence resistance) across the bilayer membrane from $\mathrm{Ag} / \mathrm{AgCl}$ electrodes (one in each electrolyte compartment of the chamber) using an Axopatch $200 \mathrm{~B}$ amplifier from Axon Instruments, Union City, CA connected to an acquisition board with a sampling rate of $100 \mathrm{kHz}$ (Digidata 1322A, Axon Instruments) and a computer with Clampex software (Axon Instruments). To reduce the electric current noise we used either the capacitive feedback amplification ("patch mode" setting, gain $\beta=1$ ) or, typically, the resistive feedback amplification with the $500 \mathrm{M} \Omega$ feedback resistor ("whole cell mode" setting, gain $\beta=1$ ) in combination with the low-pass filter of the amplifier with a cutoff frequency of $10 \mathrm{kHz}$. Before adding alamethicin and its derivative to the bilayer we confirmed that the bilayers were stable (i.e. no detectable leak currents or increased noise levels) for several minutes at transmembrane potentials up to $0.2 \mathrm{~V}$. Both bilayer chambers could be stirred with stir bars (using a Stir-2 stir plate from Warner Instruments) to ensure rapid mixing after addition of molecules to the bilayer chambers. In order to reach equilibrium conditions of binding, we waited at least $15 \mathrm{~min}$ (often more than $30 \mathrm{~min}$ ) after addition of $\mathbf{8}$, CA II, or $\mathbf{9}$ before performing quantitative recordings of current. We did not wash the recording chambers between additions of molecule $\mathbf{8}$, CA II, or $\mathbf{9}$ in order to keep the total concentration of all molecules well defined. Throughout the recordings we monitored the capacitance of the bilayers using the built-in capacitance compensation of the Axopatch $200 \mathrm{~B}$ amplifier.

\section{Supplementary Material}

Refer to Web version on PubMed Central for supplementary material.

\section{Acknowledgements}

We acknowledge the National Institute of Health grants GM065364 and GM051559 for support. M. M. acknowledges the Novartis Foundation for a postdoctoral fellowship. This material is also based upon work supported by a National Science Foundation CAREER Award (M.M., grant No. 0449088) and by a research grant from IMRA America and AISIN USA.

\section{References}

1. Fox RO Jr. Richards FM. Nature 1982;300:325-330. [PubMed: 6292726]

2. Boheim G, Benz R. Biochim. Biophys. Acta 1978;507:262-270. [PubMed: 626734]

3. Sansom MSP. Eur. Biophys. J 1993;22:105-124. [PubMed: 7689461]

4. Mayer, M.; Terrettaz, S.; Giovangrandi, L.; Vogel, H. Functional Analysis of Ion Channels: Planar Patch Clamp and Impedance Spectroscopy of Tethered Lipid Membranes. In: Cooper, JM.; Cass, AEG., editors. Biosensors: A Practical Approach. Vol. 2 ed.. Vol. Vol. 1. Oxford: Oxford University Press; 2003. p. 153-184.

5. Blake S, Mayer T, Mayer M, Yang J. Chembiochem 2006;7:433-435. [PubMed: 16444770]

6. Kiwada T, Sonomura K, Sugiura Y, Asami K, Futaki S. J. Am. Chem. Soc 2006;128:6010-6011. [PubMed: 16669650]

7. Bayley H, Cremer PS. Nature 2001;413:226-230. [PubMed: 11557992]

8. Das G, Talukdar P, Matile S. Science 2002;298:1600-1602. [PubMed: 12446904]

9. Litvinchuk S, Tanaka H, Miyatake T, Pasini D, Tanaka T, Bollot G, Mareda J, Matile S. Nat Mater 2007;6:576-580. [PubMed: 17558430]

10. Berkane E, Orlik F, Charbit A, Danelon C, Fournier D, Benz R, Winterhalter M. J Nanobiotechnology 2005;3:3. [PubMed: 15743521]

11. Danelon C, Lindemann M, Borin C, Fournier D, Winterhalter M. IEEE Trans Nanobioscience 2004;3:46-48. [PubMed: 15382643]

12. Aidley, DJ.; Stanfield, PR. Ion Channels. Vol. 1 ed.. Cambridge, UK: Cambridge University Press; 1996. p. 9-31.

13. Hille, B. Ion Channels of Excitable Membranes. Vol. 3 ed.. Sunderland: Sinauer Associates; 2001. p. 25-60. 
14. Mutter M, Altmann K-H, Tuchscherer G, Vuilleumier S. Tetrahedron Lett 1988;44:771-785.

15. Tuchscherer G, Steiner V, Altmann KH, Mutter M. Methods Mol. Biol 1994;36:261-285. [PubMed: 7697113]

16. Altmann KH, Mutter M. Int. J. Biochem 1990;22:947-956. [PubMed: 2282964]

17. Altmann E, Altmann KH, Nebel K, Mutter M. Int. J. Pept. Protein Res 1988;32:344-351. [PubMed: 3145251]

18. Oiki S, Danho W, Montal M. Proc. Nat. Acad. Sci. USA 1988;85:2393-2397. [PubMed: 2451248]

19. Oiki S, Danho W, Madison V, Montal M. Proc. Nat. Acad. Sci. USA 1988;85:8703-8707. [PubMed: 2460876]

20. DeGrado WF, Wasserman ZR, Lear JD. Science 1989;243:622-628. [PubMed: 2464850]

21. Akerfeldt KS, Lear JD, Wasserman ZR, Chung LA, DeGrado WF. Acc. Chem. Res 1993;26:191197.

22. Heyse S, Stora T, Schmid E, Lakey JH, Vogel H. Biochim. Biophys. Acta-Rev. Biomembranes 1998;1376:319-338.

23. Pawlak M, Meseth U, Dhanapal B, Mutter M, Vogel H. Protein Sci 1994;3:1788-1805. [PubMed: 7531528]

24. Stora T, Lakey JH, Vogel H. Angew. Chem. Int. Ed 1999;38:389-392.

25. Terrettaz S, Mayer M, Vogel H. Langmuir 2003;19:5567-5569.

26. Walker B, Kasianowicz J, Krishnasastry M, Bayley H. Protein Eng 1994;7:655-662. [PubMed: 8073035]

27. Gu LQ, Braha O, Conlan S, Cheley S, Bayley H. Nature 1999;398:686-690. [PubMed: 10227291]

28. Bayley H, Jayasinghe L. Mol. Membr. Biol 2004;21:209-220. [PubMed: 15371010]

29. Bayley H. Curr. Opin. Biotechnol 1999;10:94-103. [PubMed: 10047514]

30. Bayley H. J. Cell. Biochem 1994;56:177-182. [PubMed: 7829577]

31. Tien HT, Salamon Z, Ottova A. Crit. Rev. Biomed. Eng 1991;18:323-340. [PubMed: 2036800]

32. Rokitskaya TI, Antonenko YN, Kotova EA. FEBS Lett 1993;329:332-335. [PubMed: 7689977]

33. Walker B, Bayley H. Protein Eng 1994;7:91-97. [PubMed: 8140099]

34. Bezrukov SM, Vodyanoy I, Parsegian VA. Nature 1994;370:279-281. [PubMed: 7518571]

35. Woolley GA, Epand RM, Kerr ID, Sansom MS, Wallace BA. Biochemistry 1994;33:6850-6858. [PubMed: 7515685]

36. Cornell BA, Braach-Maksvytis VL, King LG, Osman PD, Raguse B, Wieczorek L, Pace RJ. Nature 1997;387:580-583. [PubMed: 9177344]

37. Vogel H, Jahnig F. Biophys. J 1986;50:573-582. [PubMed: 3779000]

38. Terrettaz S, Ulrich WP, Guerrini R, Verdini A, Vogel H. Angew. Chem. Int. Ed 2001;40:1740-1743.

39. Braha O, Walker B, Cheley S, Kasianowicz JJ, Song L, Gouaux JE, Bayley H. Chem. Biol 1997;4:497-505. [PubMed: 9263637]

40. Meller A, Nivon L, Brandin E, Golovchenko J, Branton D. Proc. Nat. Acad. Sci. USA 2000;97:1079_ 1084. [PubMed: 10655487]

41. Wallace BA. Biophys. J 1986;49:295-306. [PubMed: 2420381]

42. Borisenko V, Zhang Z, Woolley GA. Biochim. Biophys. Acta 2002;1558:26-33. [PubMed: 11750261]

43. Woolley GA, Zunic V, Karanicolas J, Jaikaran AS, Starostin AV. Biophys. J 1997;73:2465-2475. [PubMed: 9370440]

44. Futaki S, Zhang Y, Kiwada T, Nakase I, Yagami T, Oiki S, Sugiura Y. Bioorg. Med. Chem 2004;12:1343-1350. [PubMed: 15018906]

45. Antonenko YN, Rokitskaya TI, Kotova EA, Agapov II, Tonevitsky AG. Biochemistry (Mosc) 2004;69:220-227. [PubMed: 15000691]

46. Antonenko YN, Rokitskaya TI, Kotova EA, Reznik GO, Sano T, Cantor CR. Biochemistry 2004;43:4575-4582. [PubMed: 15078104]

47. Shapovalov VL, Rokitskaya TI, Kotova EA, Krokhin OV, Antonenko YN. Photochem Photobiol 2001;74:1-7. [PubMed: 11460529] 
48. Sansom MS. Prog. Biophys. Mol. Biol 1991;55:139-235. [PubMed: 1715999]

49. Mayer M, Kriebel JK, Tosteson MT, Whitesides GM. Biophys. J 2003;85:2684-2695. [PubMed: 14507731]

50. Schmidt C, Mayer M, Vogel H. Angew. Chem. Int. Ed 2000;39:3137-3140.

51. Zhang Y, Futaki S, Kiwada T, Sugiura Y. Bioorg. Med. Chem 2002;10:2635-2639. [PubMed: 12057652]

52. Futaki S, Fukuda M, Omote M, Yamauchi K, Yagami T, Niwa M, Sugiura Y. J. Am. Chem. Soc 2001;123:12127-12134. [PubMed: 11734010]

53. Futaki S, Zhang YJ, Sugiura Y. Tetrahedron Lett 2001;42:1563-1565.

54. Futaki S, Asami K. Chem Biodivers 2007;4:1313-1322. [PubMed: 17589883]

55. Yin P, Burns CJ, Osman PD, Cornell BA. Biosens. Bioelectron 2003;18:389-397. [PubMed: 12604256]

56. Goldermann M, Hanke W. Microgravity Sci Technol 2001;13:35-38. [PubMed: 12043748]

57. Miller, C. Ion Channel Reconstitution. Vol. 1 ed.. New York: Plenum Press; 1986. p. 131-140.

58. Shin SH, Luchian T, Cheley S, Braha O, Bayley H. Angew. Chem. Int. Ed 2002;41:3707-3709.

59. Howorka S, Movileanu L, Braha O, Bayley H. Proc. Nat. Acad. Sci. USA 2001;98:12996-13001. [PubMed: 11606775]

60. Movileanu L, Howorka S, Braha O, Bayley H. Nat. Biotechnol 2000;18:1091-1095. [PubMed: 11017049]

61. Gu LQ, Dalla Serra M, Vincent JB, Vigh G, Cheley S, Braha O, Bayley H. Proc. Nat. Acad. Sci. USA 2000;97:3959-3964. [PubMed: 10760267]

62. Huang HW. Biochim. Biophys. Acta 2006;1758:1292-1302. [PubMed: 16542637]

63. Capone R, Blake S, Rincon Restrepo M, Yang J, Mayer M. J. Am. Chem. Soc 2007;129:9737-9745. [PubMed: 17625848]

64. Krishnamurthy VM, Kaufman GK, Urbach AR, Gitlin I, Gudiksen KL, Weibel DB, Whitesides GM. Chem. Rev. 2007in press

65. Gitlin I, Mayer M, Whitesides GM. J. Phys. Chem. B 2003;107:1466-1472.

66. Colton IJ, Carbeck JD, Rao J, Whitesides GM. Electrophoresis 1998;19:367-382. [PubMed: 9551788]

67. Day YS, Baird CL, Rich RL, Myszka DG. Protein Sci 2002;11:1017-1025. [PubMed: 11967359]

68. Woolley GA, Wallace BA. J. Membr. Biol 1992;129:109-136. [PubMed: 1279177]

69. Salditt T, Li C, Spaar A. Biochim. Biophys. Acta 2006;1758:1483-1498. [PubMed: 16987495]

70. Bechinger B. J. Membr. Biol 1997;156:197-211. [PubMed: 9096062]

71. Sondermann M, George M, Fertig N, Behrends JC. Biochim. Biophys. Acta 2006;1758:545-551. [PubMed: 16696935]

72. It is also possible to apply a voltage that is below the threshold voltage while increasing the concentration of alamethicin until single channel events can be recorded.

73. Hall JE, Vodyanoy I, Balasubramanian TM, Marshall GR. Biophys. J 1984;45:233-247. [PubMed: 6324906]

74. Wassner AJ, Hurt JA, Lear JD, Akerfeldt KS. Org. Lett 2002;4:1647-1649. [PubMed: 12000264]

75. Duclohier H, Wroblewski H. J. Membr. Biol 2001;184:1-12. [PubMed: 11687873]

76. White SH. Biophys. J 1972;12:432-445. [PubMed: 5019479]

77. White SH, Thompson TE. Biochim. Biophys. Acta 1973;323:7-22. [PubMed: 4360052]

78. Akaji K, Tamai Y, Kiso Y. Tetrahedron Lett 1995;36:9341-9344.

79. Jaikaran DC, Biggin PC, Wenschuh H, Sansom MS, Woolley GA. Biochemistry 1997;36:1387313881. [PubMed: 9374865]

80. Lougheed T, Borisenko V, Hennig T, Ruck-Braun K, Woolley GA. Org. Biomol. Chem 2004;2:27982801. [PubMed: 15455152]

81. Peggion C, Coin I, Toniolo C. Biopolymers 2004;76:485-493. [PubMed: 15499566]

82. Schmitt JD, Sansom MS, Kerr ID, Lunt GG, Eisenthal R. Biochemistry 1997;36:1115-1122.

[PubMed: 9033402] 
83. You S, Peng S, Lien L, Breed J, Sansom MS, Woolley GA. Biochemistry 1996;35:6225-6232. [PubMed: 8639562]

84. Woolley GA, Biggin PC, Schultz A, Lien L, Jaikaran DC, Breed J, Crowhurst K, Sansom MS. Biophys. J 1997;73:770-778. [PubMed: 9251793]

85. Woolley GA, Jaikaran ASI, Zhang ZH, Peng SY. J. Am. Chem. Soc 1995;117:4448-4454.

86. Brullemans M, Tancrde P. Biophys. Chem 1987;27:225-231. [PubMed: 17010291]

87. Hanke W, Boheim G. Biochim. Biophys. Acta 1980;596:456-462. [PubMed: 6153907]

88. Motulsky, H.; Christopoulos, A. Fitting Models to Biological Data Using Linear and Nonlinear Regression: A Practical Guide to Curve Fitting. Vol. 1 ed.. New York: Oxford University Press; 2004. p. 193

89. Lauffenburger, DA.; Linderman, JJ. Receptors. New York: Oxford University Press; 1993. p. 23

90. We tested the validity of the simplification that we made in equation 11 by performing the same analysis and fit of the data in Figure $6 \mathrm{~B}$ without any simplification. In this case, we used equation 10 to obtain $[\mathrm{CA} \mathrm{II}]_{\mathrm{eq}}$, which then lead to a quadratic equation to solve for $[\mathbf{8}]_{\mathrm{eq}}$ of the form: $[\mathbf{8}]_{\mathrm{eq}}$ $=\left(-\left(1-K_{a 8}[\mathbf{8}]_{\mathrm{eq}}+K_{a 8}[\mathrm{CA} \mathrm{II}]_{0}\right)+\left(\left(1-K_{a 8}[\mathbf{8}]_{\mathrm{eq}}+K_{a 8}[\mathrm{CA} \mathrm{II}]_{0}\right)^{2}+4 K_{a 8}[\mathbf{8}]_{\mathrm{eq}}\right)^{0.5}\right) /\left(2 K_{a 8}\right)$. Using this precise analysis, we obtained $K_{a 8}=(6.71 \pm 1.53) * 10^{5} \mathrm{M}^{-1}$ and hence the same mean value for $K_{a 8}$ as the one we obtained by using the simplification in equation 11.

91. Connors, KA. Binding Constants: The Measurement of Molecular Complex Stability. New York: John Wiley \& Sons; 1987. p. 339-362.

92. Motulsky, H.; Christopoulos, A. Fitting Models to Biological Data Using Linear and Nonlinear Regression: A Practical Guide to Curve Fitting. Vol. 1 ed.. New York: Oxford University Press; 2004. p. 210-217.

93. Motulsky, H.; Christopoulos, A. Fitting Models to Biological Data Using Linear and Nonlinear Regression: A Practical Guide to Curve Fitting. Vol. 1 ed.. New York: Oxford University Press; 2004. p. 256-260.

94. HillSlope can be interpreted as follows: A HillSlope with a value of 1.0 means that the $y$-value of a dose-response curve increases from $10 \%$ to $90 \%$ of $y_{\max }$, if the $x$-value increases by a factor of 81 . A dose-response curve with a HillSlope of 1.0 is called a standard dose-response curve. A HillSlope greater than 1.0 means that the dose-response curve is steeper than this standard curve, while a HillSlope smaller than 1.0 means that the curve is shallower than this standard curve.

95. Motulsky, H.; Christopoulos, A. Fitting Models to Biological Data Using Linear and Nonlinear Regression: A Practical Guide to Curve Fitting. Vol. 1 ed.. New York: Oxford University Press; 2004. p. 38-39.

96. Note, a HillSlope with a value significantly different from 1 usually implies that standard mechanistic mass-action models do not apply and consequently it is difficult to interpret the $I C_{50}$ value. Typically this analysis is, however, performed under the assumption that the concentration of the competitive inhibitor does not change upon binding (i.e., here this would mean that $[\mathbf{9}]_{\mathrm{eq}}=[\mathbf{9}]_{0}$ ), whereas in the example we show, a significant fraction of 9 bound to CA II. The fact that Figure 7 was not plotted as a function of $\log \left([9]_{\mathrm{eq}}\right)$ may contribute to the deviation of the Hillslope from unity.

97. Linden J. J. Cyclic Nucleotide Res 1982;8:163-172. [PubMed: 6762384]

98. Jeon TJ, Malmstadt N, Schmidt JJ. J. Am. Chem. Soc 2006;128:42-43. [PubMed: 16390112]

99. White, SH. The physical nature of planar bilayer membranes. In: Miller, C., editor. Ion Channel Reconstitution. Vol. 1 ed.. Vol. Vol.. New York: Plenum Press; 1986. p. 3-35.

100. Malmstadt N, Nash MA, Purnell RF, Schmidt JJ. Nano Lett 2006;6:1961-1965. [PubMed: 16968008]

101. Fertig N, Meyer C, Blick RH, Trautmann C, Behrends JC. Phys. Rev. E 2001;64040901-040901-040901-040904

102. Fertig N, Blick RH, Behrends JC. Biophys. J 2002;82:3056-3062. [PubMed: 12023228]

103. Fertig N, Klau M, George M, Blick RH, Behrends JC. Appl. Phys. Lett 2002;81:4865-4867.

104. Borisenko V, Lougheed T, Hesse J, Fertig N, Behrends JC, Woolley A, Schuetz GJ. Biophys. J 2003;84:612-622. [PubMed: 12524314]

105. Wilk SJ, Petrossian L, Goryll M, Thornton TJ, Goodnick SM, Tang JM, Eisenberg RS. Biosens. Bioelectron 2007;23:183-190. [PubMed: 17507211] 
106. Shim JW, Gu LQ. Anal. Chem 2007;79:2207-2213. [PubMed: 17288404]

107. Quist AP, Chand A, Ramachandran S, Daraio C, Jin S, Lal R. Langmuir 2007;23:1375-1380. [PubMed: 17241061]

108. Funakoshi K, Suzuki H, Takeuchi S. Anal. Chem 2006;78:8169-8174. [PubMed: 17165804]

109. Suzuki H, Tabata KV, Noji H, Takeuchi S. Biosens. Bioelectron 2007;22:1111-1115. [PubMed: 16730973]

110. Suzuki H, Tabata K, Kato-Yamada Y, Noji H, Takeuchi S. Lab Chip 2004;4:502-505. [PubMed: 15472735]

111. Lougheed T, Borisenko V, Hand CE, Woolley GA. Bioconj. Chem 2001;12:594-602.

112. Bayley H. Nat. Chem. Biol 2006;2:11-13. [PubMed: 16408083]

113. Uram JD, Ke K, Hunt AJ, Mayer M. Small 2006;2:967-972. [PubMed: 17193151]

114. Uram JD, Ke K, Hunt AJ, Mayer M. Angew. Chem. Int. Ed 2006;45:2281-2285.

115. Uram JD, Mayer M. Biosens. Bioelectron 2007;22:1556-1560. [PubMed: 16889953]

116. Avila LZ, Chu YH, Blossey EC, Whitesides GM. J. Med. Chem 1993;36:126-133. [PubMed: 8421278]

117. Roy BC, Mallik S. J. Org. Chem 1999;64:2969-2974. [PubMed: 11674380]

118. Dess DB, Martin JC. J. Org. Chem 1983;48:4155-4156.

119. Schlue, WR.; Hanke, W. Planar Lipid Bilayers. Vol. 1 ed.. London: Academic Press; 1993. p. 60-78.

120. Tosteson MT, Chow M. J. Virol 1997;71:507-511. [PubMed: 8985378]

121. Montal M, Mueller P. Proc. Nat. Acad. Sci. USA 1972;69:3561-3566. [PubMed: 4509315]

122. Alvarez, O. How to Set Up a Bilayer System. In: Miller, C., editor. Ion Channel Reconstitution. Vol. 1 ed.. Vol. Vol.. New York: Plenum Press; 1986. p. 115-130. 
$8_{\text {solution }}$

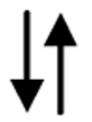

$\mathbf{8}_{\text {bilayer }}$

14

$8_{\text {pore }}$

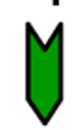

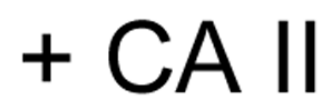

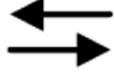

CA II-8

solution

$\downarrow \uparrow$
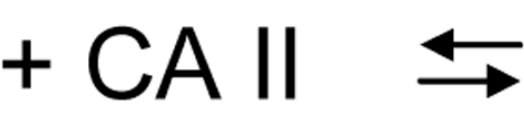

CA II- $8_{\text {bilayer }}$

\section{current}
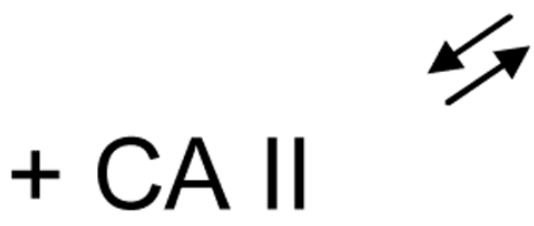

Figure 1.

Chain of equilibria of alamethicin-sulfonamide $(\mathbf{8})$ in a recording chamber for planar lipid bilayer recordings. Only the molecules of $\mathbf{8}$ that self-assembled to a pore in the bilayer, $\mathbf{8}_{\text {pore }}$, can facilitate current through the membrane. CA II can bind to molecules of $\mathbf{8}$ in all "compartments" (i.e., in solution, in the bilayer, or in the pore) to form the complex CA II-8. Note, however, that according to the model that we propose in this work, binding of CA II to molecules of $\mathbf{8}$ which are in a conducting pore, effectively removes $\mathbf{8}_{\text {pore }}$ from the pore. It is possible that binding of CA II to $\mathbf{8}_{\text {pore }}$ results transiently in the blockage of a pore; we

hypothesize, however, that due to the bulkiness of the CA II-8 complex, it is not likely that, in steady state conditions, complexes of CA II-8 remain a part of fully assembled pores. Instead, we propose that CA II-8 complexes will be present in one of the other two compartments (i.e., in the solution or in the bilayer). In addition, binding of CA II to 8 in the solution or in the bilayer, effectively reduces the concentration of free $\mathbf{8}$ in all three compartments and hence shifts the equilibria such that ultimately the concentration of $\mathbf{8}_{\text {pore }}$ is reduced and consequently the transmembrane current is reduced as well. 


\section{A}
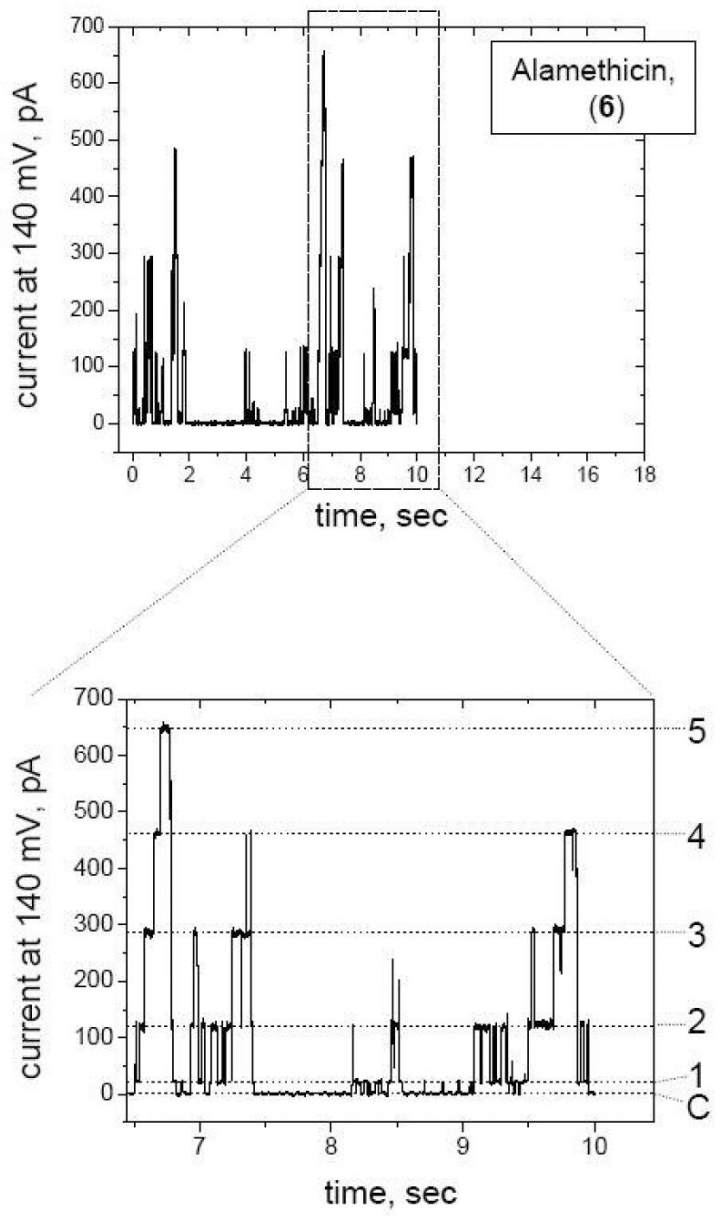

B
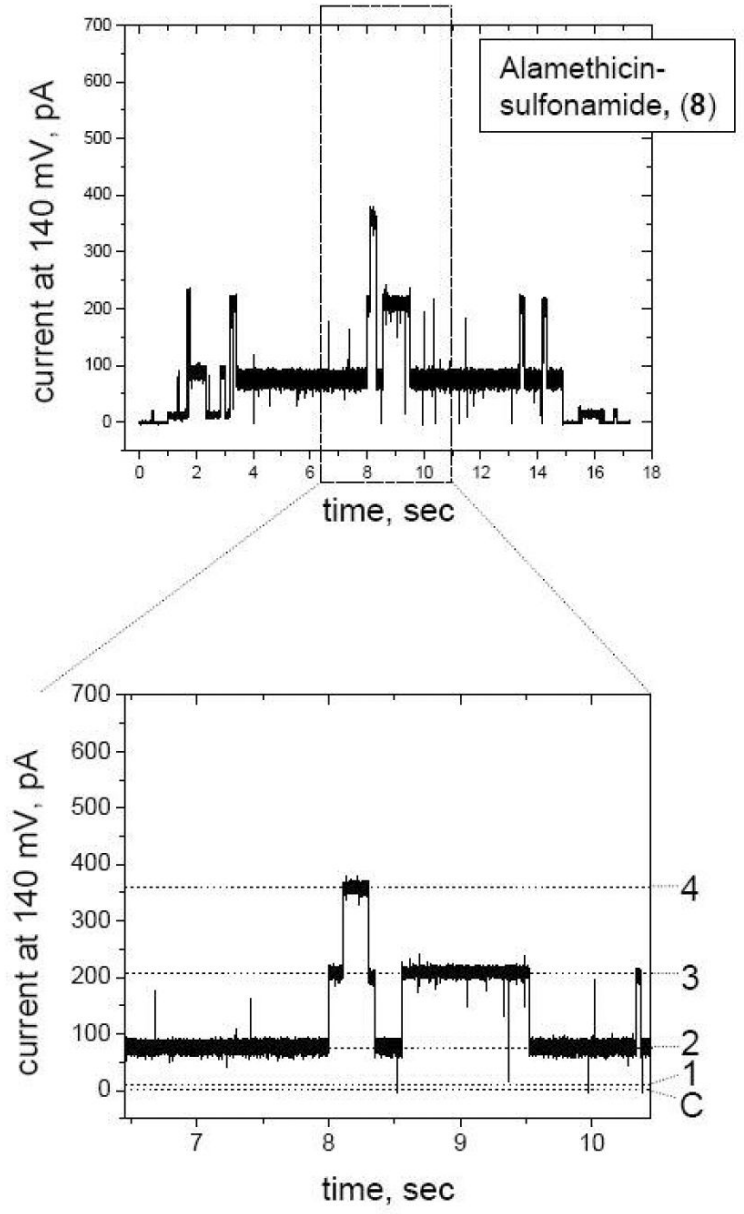

Figure 2.

Comparison of single-channel recordings of $\mathbf{8}$ with recordings of native alamethicin (6). A) Single-channel current of native alamethicin (fraction F30). B) Single-channel current of $\mathbf{8}$, recorded under the same conditions as (A) and shown at the same scaling of the axes. Note the well-defined conductance states, the increased life-time of individual conductance states (14; "C" stands for closed state), and the increased current noise of $\mathbf{8}$ compared to native alamethicin. We used a low-pass filter with a cutoff frequency of $10 \mathrm{kHz}$ and a sampling rate of $100 \mathrm{kHz}$ for both recordings. 

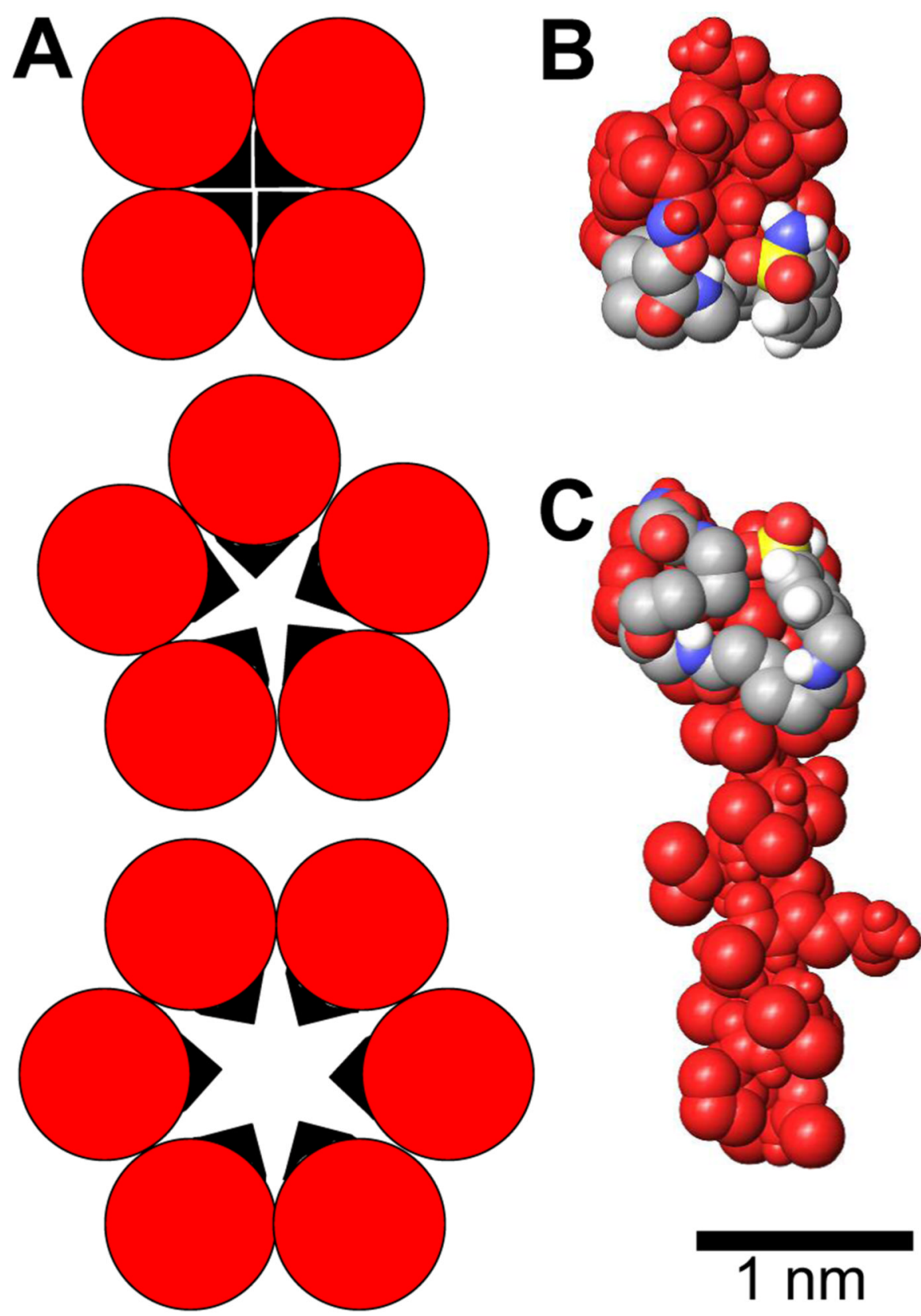

Figure 3.

Simplified model of pores of alamethicin-sulfonamide $(\mathbf{8})$ and energy minimized representations of $\mathbf{8}$. A) Top view of pores of $\mathbf{8}$ represented as a circular assembly of cylinders that form a central pore in a lipid bilayer. In this cartoon, the red disks represent the alamethicin part of $\mathbf{8}$ and the black triangles represent the sulfonamide moiety with its linker (5); for clarity, all sulfonamide groups were positioned to face the lumen of the channel. The cartoon illustrates that the fraction of the cross-sectional area of the lumen that is occupied by sulfonamide groups decreases with increasing number of channel-forming peptides in the assembly. This cartoon is not drawn to scale and the smallest conducting pore of $\mathbf{8}$ may be composed of 3 to 5 molecules of $8{ }^{49} \mathrm{~B}$ ) Top view representation of an energy minimized structure of 8 (the carbon atoms 
of the sulfonamide moiety are shown in grey). C) Corresponding side view representation of 8. The scale bar refers to the structural representations of $\mathbf{8}$ shown in (B) and (C). 
A
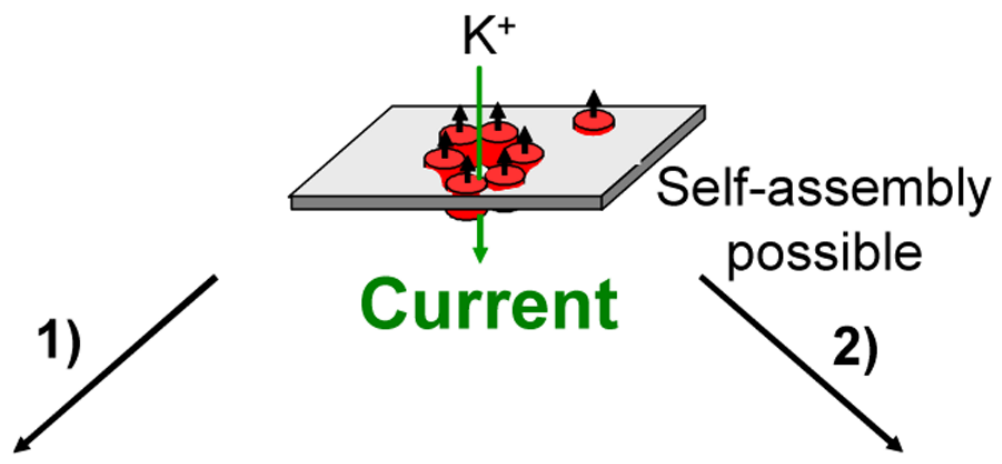

Current possible
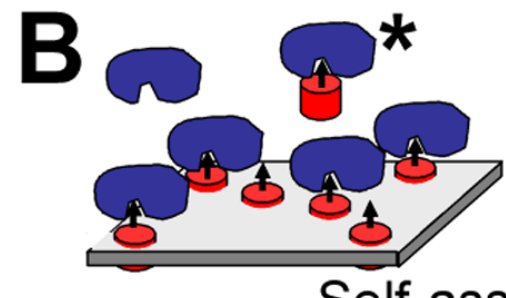

\section{No current}

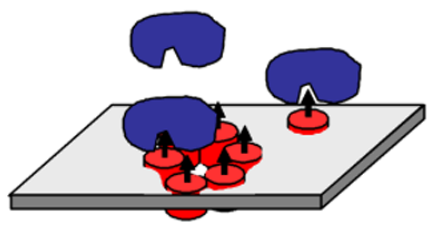

Self-assembly

disrupted
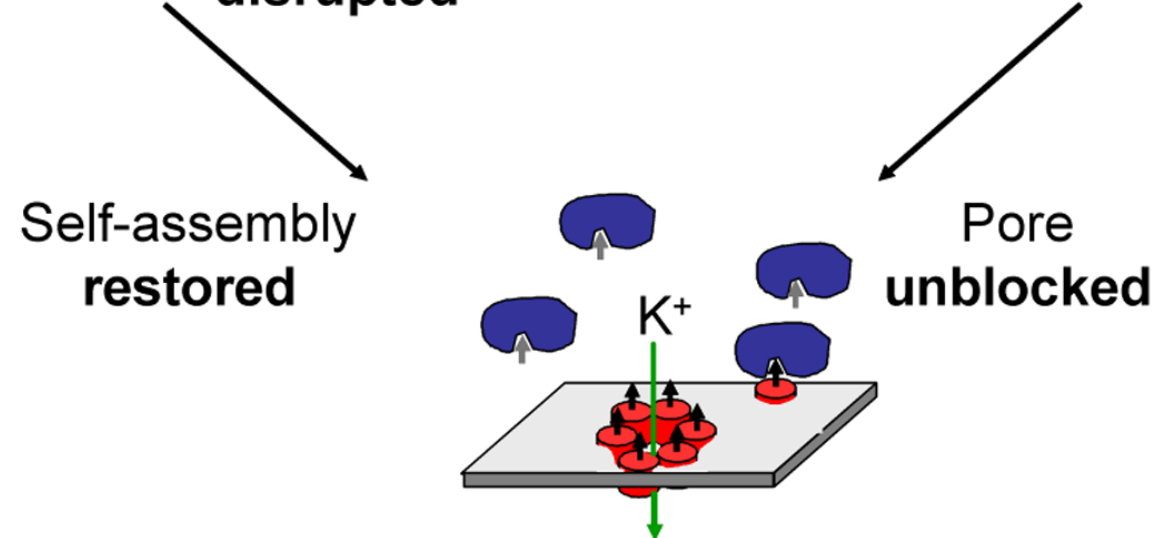

Pore

C

blocked

Current

Figure 4.

Cartoon illustrating the concept of sensing by binding of analyte to a functionalized ion channel-forming peptide. A) Monomers of $\mathbf{8}$ (red cylinders) with covalently attached ligands (small black arrows) self-assemble to form pores in a planar lipid bilayer. The current (flux of ions) through single or multiple pores is recorded with a patch clamp amplifier. B) Addition of a macromolecule (here CA II, represented in blue) that binds to the ligand, may have two consequences: 1) it may disrupt the pore, either by steric hindrance, or by removing the peptide from the bilayer (see asterisk), or 2) it may bind close to the mouth of the pore and block it. In either case, only a small (or no) current would be recorded as a result of the interaction. C) Addition of competitive ligand (here 9, small grey arrows) to the solution leads to binding of free ligand to the proteins, and releases ion channel-forming peptides. This action makes it 
possible for the peptides to self-assemble again to a conducting pore, or it unblocks an existing pore that was blocked by the protein. 

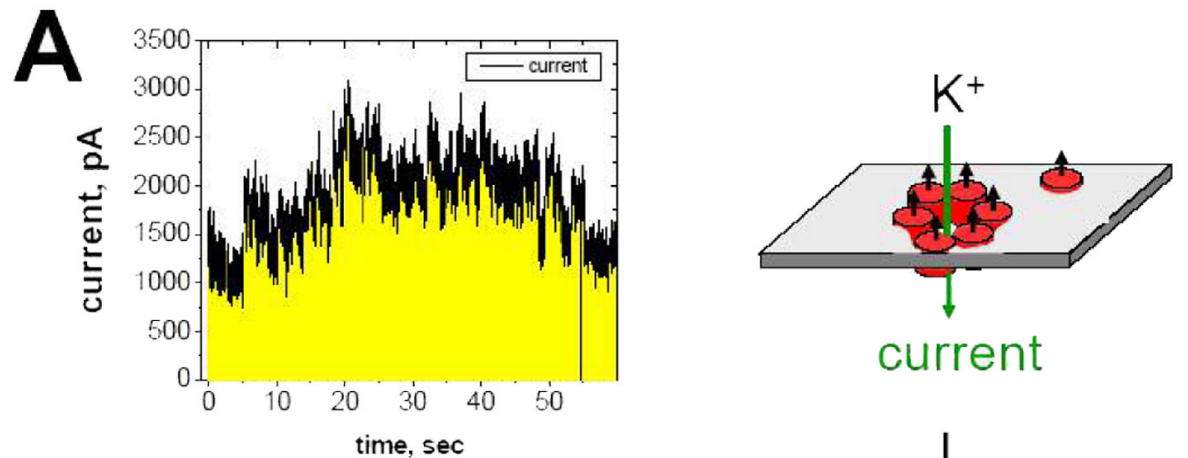

B
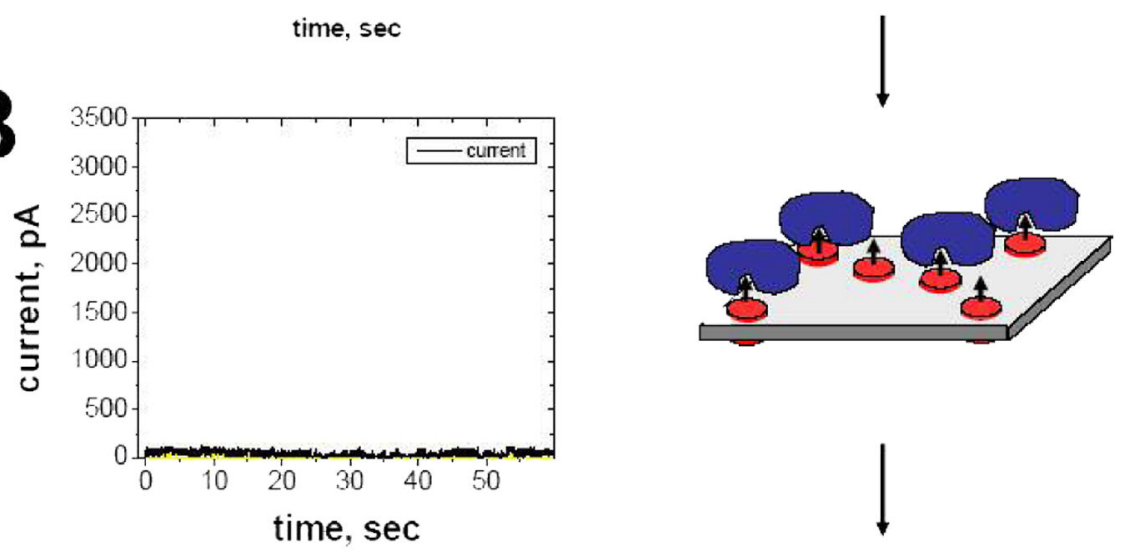

0
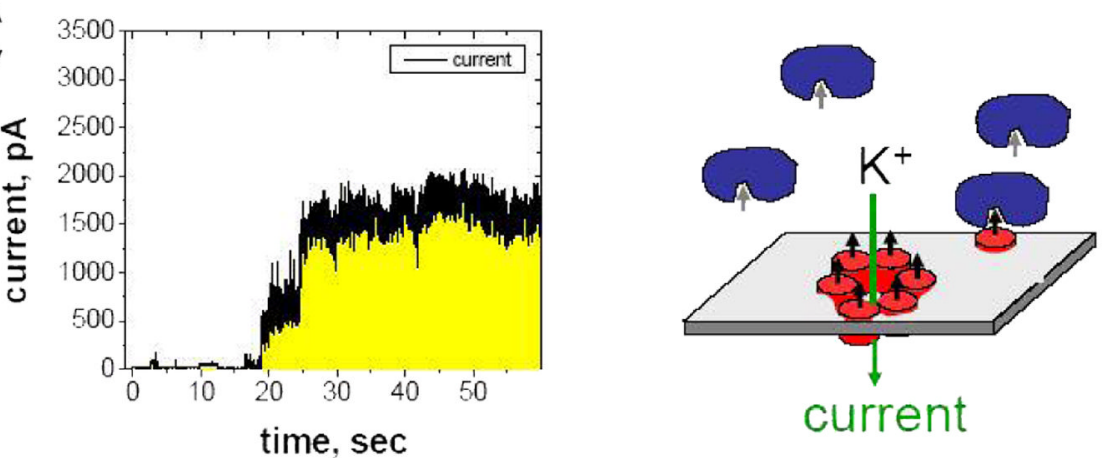

Figure 5.

Detection of CA II by disruption (or blocking) of self-assembled ion channels and restoration of ion-channel activity upon addition of competitive inhibitor 9. A) Original trace of current versus time illustrating the macroscopic current through many pores of $\mathbf{8}$ (concentration in the chamber $40 \mathrm{ng} \mathrm{mL}^{-1}$ or $16.1 \mathrm{nM}$ ) before addition of CA II. B) Original trace of current versus time after addition of $\sim 1 \mu \mathrm{M}$ CA II. C) Original trace of current versus time recorded after shortly after addition of $31.2 \mu \mathrm{M}$ 9. The applied potential was $+140 \mathrm{mV}$ for all recordings. The cartoons next to the current versus time traces show possible arrangements of $\mathbf{8}$, CA II, and 9. Note that the current traces shown here are only $1 \mathrm{~min}$ long; to increase the reproducibility of the quantification of the transported charge, we increased the interval for time-averaging to 5 min for all quantitative recordings in this work. 


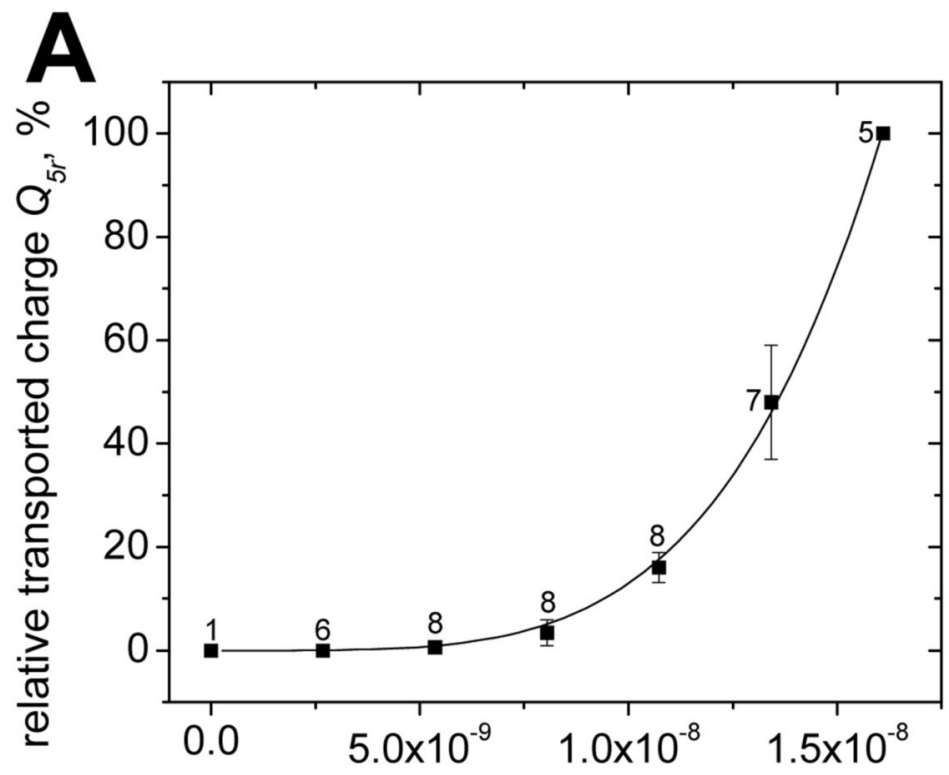

[8], M

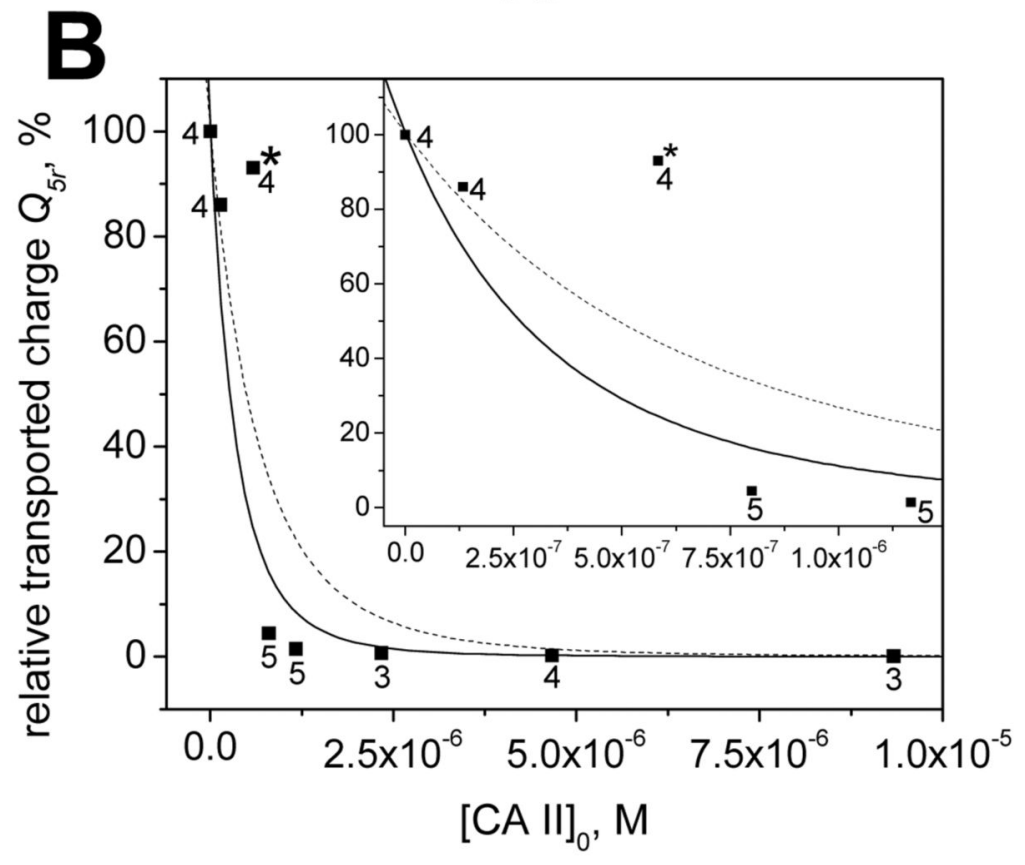

Figure 6.

Ion flux through lipid bilayers after self-assembly of ion channels and disruption of selfassembly (or blockage of channels) as a function of increasing concentration of $\mathbf{8}$ and CA II. A) Relative transported charge through the bilayer during a period of $5 \mathrm{~min}, Q_{5 r}=\left(Q_{5}\right)$ $\left.Q_{5 \max }\right) \cdot 100 \%$, as a function of increasing concentrations of $\mathbf{8}$ in both compartments of the recording chamber (note, before addition of CA II, $[\mathbf{8}],[\mathbf{8}]_{0}$, and $[\mathbf{8}]_{\mathrm{eq}}$ were the same). Where $Q_{5}$ represents the total charge transported through the bilayer during $5 \mathrm{~min}$ of recording at the concentration of free $\mathbf{8}$ indicated in the graph and $Q_{5 \max }$ represents the charge transported through the bilayer during 5 min of recording when the maximum concentration of free $\mathbf{8}$ was present in the chambers $(16.1 \mathrm{nM})$. The line represents a best fit of the data to equation 4 . B) 
Relative transported charge $Q_{5 r}$ as a function of increasing total concentration of CA II, [CA $\mathrm{II}]_{0}$, in both compartments of the recording chamber. Both chambers contained $1.61 \cdot 10^{-8} \mathrm{M}$ 8. The solid line represents a best fit of the data to equation 14 (the point marked with an asterisk was excluded from this best curve fit). The dashed line represents a best fit of all the data to equation 14 (including the point marked with an asterisk). The inset shows the first five data in detail. Points represent mean values of $Q_{5}$; the number next to each point indicates how many repetitions were performed to calculate the mean value of $Q_{5 r}$. Mean values that were calculated from at least seven repetitions are shown with the standard deviation (error bars). For all other points, the variation in values of $Q_{5 r}$ was typically within $\pm 20 \%$ of $Q_{5 \max }$. 


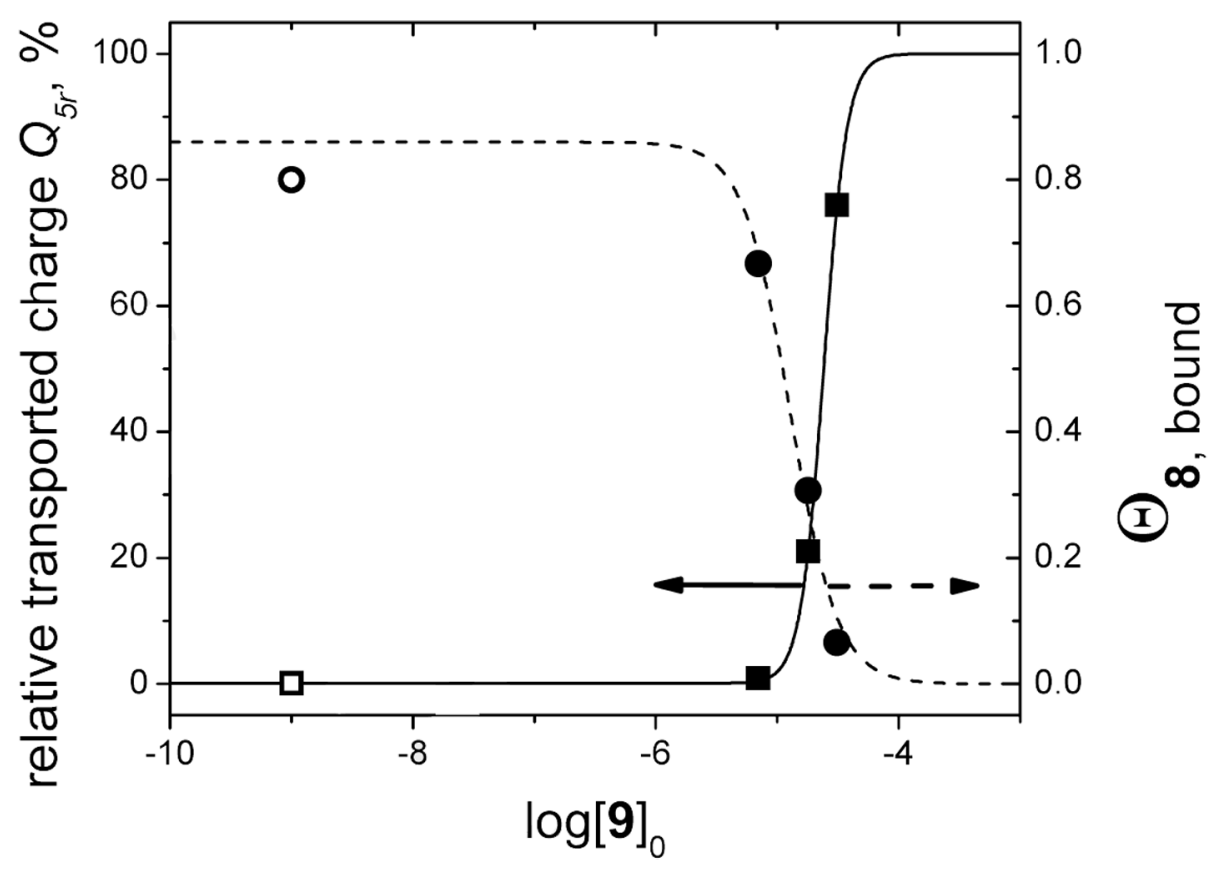

Figure 7.

Relative transported charge $Q_{5 r}$ as a function of increasing concentration of competitive inhibitor 9 in both compartments of the recording chamber. Both chambers initially contained $[8]_{0}=16.1 \mathrm{nM}$ and $[\mathrm{CA} \mathrm{II}]_{0}=9.3 \mu \mathrm{M}$. The solid curve represents a sigmoidal best fit to equation 15. This function approaches $Q_{5 r}=100 \%$ for large concentrations of [9] $]_{0}$, as expected in the presence of an excess of competitor $\mathbf{9}$, which would release all $\mathbf{8}$ from the complex with CA II $\left(K_{d \boldsymbol{9}}=0.73 \pm 0.02 \mu \mathrm{M}^{67}\right)$. The data shown as round symbols represent the fraction of $\mathbf{8}$ bound $\left(\Theta_{\boldsymbol{8}}\right.$, bound $)$ to CA II as a function of $[9]_{0}$. The values for $\Theta_{\boldsymbol{8}}$, bound were calculated from $Q_{5 r}$ for every value of [9] $]_{0}$ using equation 7 and equation 16 . The $I C_{50}$ value for the displacement of $\mathbf{8}$ from CA II by adding increasing concentrations of competetive ligand $\mathbf{9}$ was determined with a best fit analysis of the round points with equation 17 (dotted curve). Note the logarithmic scale for $[9]_{0}$. As recommended by Motulsky and Christopoulos, we chose, somewhat arbitrarily, $\log \left([\mathbf{9}]_{0}\right)=-9$ for $[\mathbf{9}]_{0}=0 \mathrm{M}$, since $\log (0)$ is not defined; 92 the corresponding data are marked by open symbols. The data in this figure were recorded only once: hence the absence of error bars. 
<smiles>NS(=O)(=O)c1ccc(CNC(=O)CCCCC(=O)O)cc1</smiles>

1<smiles>CC(COCN)(COC(=O)OCc1ccccc1)NOCc1ccccc1</smiles>

2

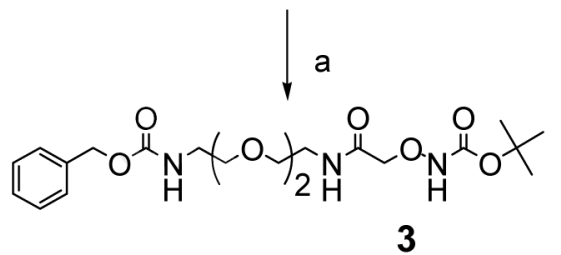
Ac-Aib-Pro-Aib-Ala-Aib-Ala-GIn-Aib-Val-
Aib-Gly-Leu-Aib-Pro-Val-Aib-Aib-Glu-Gln-N

alamethicin, 6

e

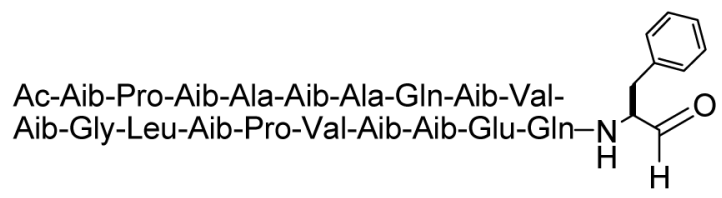

7

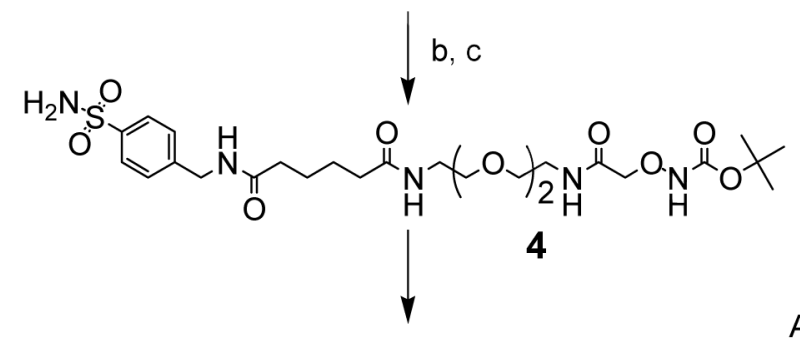

d<smiles>CC(C)(COC(C)(C)NC(=O)CON)NC(=O)CCCCC(=O)NCc1ccc(S(N)(=O)=O)cc1</smiles>

5<smiles>NS(=O)(=O)c1ccc(CNC(=O)CCCCC(=O)NCCOCCOCCNC(=O)CON=C(Cc2ccccc2)Cc2ccccc2)cc1</smiles><smiles>NS(=O)(=O)c1ccc(C(=O)O)cc1</smiles>

\section{4-carboxybenzenesulfonamide, 9}

Scheme 1.

Synthesis of an alamethicin derivative carrying a benzenesulfonamide group. Reagents and conditions: (a) (Boc-aminooxy)acetic acid, EDC, DIEA, DMF (b) Pd/C, $\mathrm{H}_{2}, \mathrm{EtOH}$ (c) 1, EDC, DIEA, DMF (d) TFA (e) Dess-Martin oxidation, $\mathrm{CH}_{2} \mathrm{Cl}_{2}$ (f) $\mathbf{5}, \mathrm{CH}_{3} \mathrm{OH}$. 